\title{
To be or not to be elided: VP ellipsis revisited
}

\section{Abstract}

The main question that this paper addresses is: what happens to nonfinite auxiliaries under English VP ellipsis (VPE)? Do they remain overt like finite auxiliaries, or do they disappear together with lexical verbs? Akmajian \& Wasow (1975) and Sag (1976) observed the following pattern: nonfinite have always stays overt, being is obligatorily elided, and be and been are optionally elided. We provide an analysis for this pattern.

As preliminaries for our account we follow Chomsky (1993) and Lasnik (1995b) in assuming that English auxiliaries carry uninterpretable inflectional features which force the auxiliary to raise to the relevant inflectional head for feature checking at PF.

As we argue that VPE includes the progressive projections in the ellipsis site, but nothing higher, the have and being data automatically fall out: have is base-generated outside the ellipsis site, so is never elided, whilst being's landing site is inside the ellipsis site, so being is always elided. For be and been, which are base-generated in the ellipsis site and raise out of it to get their inflectional features checked, we take an optional raising approach: in non-elliptical sentences raising is obligatory, otherwise the derivation crashes at PF because of unchecked features. Ellipsis contexts, on the other hand, provide the option of not raising for be and been, because ellipsis then deletes be and been in their base positions, along with their unchecked features, avoiding the PF violation.

We extend this account to other phenomena, such as VP fronting, tag questions, pseudoclefts and predicate inversion. Furthermore, we speculate that progressive aspect is in fact part of the predicate layer of the clause. This implies that the target of VPE can be characterised as the highest predicate projection of the clause, which makes VPE actually predicate ellipsis. 


\section{Introduction: the puzzle}

VP ellipsis (VPE) typically involves non-pronunciation of the verb phrase. This phenomenon, which has already been widely discussed for English in the literature, is illustrated in (1). The second conjunct of this sentence is interpreted as "... and Peter was hassled by the police, too", but the verb phrase is omitted because there is a salient antecedent in the first conjunct that renders the verb phrase in the second conjunct interpretable for the hearer (in fact, repetition of the full verb phrase often feels redundant).

(1) Betsy was hassled by the police, and Peter was, too.

In English VPE it is quite clear that finite auxiliaries cannot be elided, as in (2)a,b. The lexical verb, on the other hand, cannot survive ellipsis. ${ }^{1}$ Even when finite, the English lexical verb is still elided under VPE, leading to insertion of the finite dummy auxiliary $d o$, see (2)c,d.

(2) a. An elephant can't fly, but maybe a rhino *(could) [fly]. ${ }^{2}$

b. I thought the auxiliary hadn't disappeared, but it *(had) [disappeared].

c. * The chicken didn't put the tuna on the table, but the penguin put [the tuna on the table].

d. The chicken didn't put the tuna on the table, but the penguin did [put the tuna on the table].

\footnotetext{
${ }^{1}$ Unlike with Verb-stranding VPE in languages such as Portuguese (see Cyrino \& Matos 2005).

${ }^{2}$ We indicate a VP ellipsis site with strike-through. This notation is mainly used here for clarity, although our approach does adopt a PF deletion analysis of VPE.
} 
This is why it has been assumed that either finite auxiliaries or finite $\mathrm{T}$ act as the licensor for VPE, and that what is elided is VP, or more recently vP (Zagona 1982, 1988; Lobeck 1995; Johnson 2001; Gengel 2007; Aelbrecht 2010), as is schematized in (3):

(3) Betsy was hassled by the police, and [тр Peter [т was [

The question this paper addresses is: what happens to nonfinite auxiliaries under VPE: do they pattern with the finite auxiliary and survive ellipsis, or do they disappear just like the lexical verb? Consider the maximum range of auxiliaries that one clause can contain, as exemplified in (4)a with (4)b as a schematic summary of the auxiliary sequence. ${ }^{3}$

(4) a. Betsy must have been being hassled.

b. finite modal $>$ perfect $\mathrm{HAVE}>$ progressive $\mathrm{BE}>$ passive $\mathrm{BE}>$ lexical verb

Sag (1976) and Akmajian \& Wasow (1975) observed that when VPE is applied to such an auxiliary sequence, not all auxiliaries behave alike, as (5) shows (from Sag 1976:31). Specifically, they assume that perfect have cannot be elided (see (5)a), whilst been can be optionally elided (see $(5) b, c) .{ }^{4}$ Being, on the other hand, is obligatorily included in the ellipsis site, (see (5)d). The table in (6) below summarises this pattern.

\footnotetext{
${ }^{3}$ The auxiliary types (perfect, progressive, passive), abstracting away from surface forms, are indicated with capitals, whereas the actual morphological forms (have, be, being, was etc) will be given in italics.

${ }^{4}$ There is some discussion in the literature on whether or not the non-finite perfect auxiliary have can be elided under VPE. We address this issue in more detail in section 3.2. As the results of our exploration will be that have generally cannot be elided, we agree with the pattern observed by Sag (1976) and Akmajian and Wasow (1975), though admit that some dialectal variation may be involved.

As pointed out by an anonymous reviewer, the obligatory deletion of being could also be contested. Again, we keep the original pattern in mind as the one our analysis has to account for, and come back to the potential non-deletion of being in section 7.1 at the end of this paper.
} 
(5) Betsy must have been being hassled by the police, and...
a. * Peter must have been being hassled by the police, too.
b. Peter must have been being hassled by the police, too.
c. Peter must have been being hassled by the police, too.
d. * Peter must have been being hassled by the police, too.

(6)

\begin{tabular}{|l|l|l|l|l|l|l|}
\hline & modal/finite aux & have & be $^{5}$ & been & being & lexical verb \\
\hline elided & $*$ & $*$ & $\checkmark$ & $\checkmark$ & $\checkmark$ & $\checkmark$ \\
\hline remaining & $\checkmark$ & $\checkmark$ & $\checkmark$ & $\checkmark$ & $*$ & $*$ \\
\hline
\end{tabular}

Table 1: Deletion of verbal elements in VP ellipsis

Since this pattern was first discovered, it has received little to no attention. ${ }^{6}$ The aim of this paper therefore is to account for this pattern. The puzzle thus consists of three parts which an adequate analysis of English VPE has to cover. It needs to explain why VPE (i) never deletes have, (ii) optionally elides be/been, and (iii) always elides being. Our main claims are that VPE targets the progressive aspectual layer (when present), that optional auxiliary deletion is the result of optional auxiliary raising out of the ellipsis site and rescue by PF-deletion in the case of non-raising, and finally, that VPE should be viewed as predicate ellipsis. ${ }^{7}$

\footnotetext{
${ }^{5}$ The data in (5) do not actually mention the behaviour of non-finite be. As is illustrated in section 3.1, however, this auxiliary patterns similar to been in that it can also be optionally elided.

${ }^{6}$ See, however, Akmajian, Steele \& Wasow (1979) for an analysis, as well as Sailor (2012), Thoms (2012) and Bošković (to appear). In sections 4, 5 and 7 we discuss these approaches and their major drawbacks.

${ }^{7}$ We purposely only discuss VPE in finite clauses and stay away from infinitival clauses and gerunds. The judgements we collected on such clauses were too inconsistent to draw any generalisations from. We do not go into this issue here, and refer the interested reader to Thoms (2011: section 3.5.1) for a thorough discussion. Thoms notes as well that VPE in infinitivals behaves differently from finite VPE in some respects and similarly in others. Although we do not agree with his conclusion that perhaps infinitival VPE involves a null proform instead of PF deletion, we adhere to his suggestion that we might not want to capture all cases of VPE with one and the same analysis. One argument in favour of a different approach is that Hebrew only allows for VPE in finite clauses. As for VPE in gerunds, there too the data are not clear. Thoms (2011: footnote 23) already
} 
Section 2 discusses some preliminaries needed for our analysis regarding the structure of the English verbal domain. The analysis itself is presented in sections 3 and 4, where we also show ways in which this approach is superior to other recent analyses of the data. Section 5 extends this account to related phenomena, namely VP fronting, pseudo-clefting, predicate inversion and tag questions. In section 6 we formalise our analysis in terms of predicate ellipsis, adopting Bowers' $(1993,2001,2002)$ definition of the predicate and using the [E]feature proposed by Merchant (2001) in combination with Grimshaw's $(2000,2005)$ extended projections. Section 7 tackles some remaining issues, and section 8 concludes.

\section{Preliminary ingredients of the analysis}

\subsection{The structure of the verb phrase}

Following Cinque (1999), Harwood (2011, 2012, to appear) and Bošković (to appear), we take (7)a to have the structure in (7)b. Here, only the subject occupies its surface position. The capitalised auxiliaries are the abstract, uninflected verb forms in their base positions.

Crucially, we assume a modal layer just below $\mathrm{T}^{\circ}$, which precedes the perfect aspectual layer, which itself precedes the progressive aspectual layer, which precedes the Voice layer, which precedes VP. We also assume a paired layering in which each layer is comprised of two projections. The higher of the two projections is headed by the relevant auxiliary verb, whilst the lower projection licenses the inflectional form of the following verb.

Concretely, we take modals to be merged in their own independent ModP, whose head selects an infinitival phrase (InfP) licensing infinitival verb forms. The aspectual auxiliaries 
(perfect have and progressive be) are inserted in their own $\mathrm{vP}_{\text {perf }}$ and $\mathrm{vP}_{\text {prog }}$ shells, which select an aspectual PerfP and ProgP, respectively, licensing perfect and progressive verb forms. We also assume that these aspectual projections encode aspectual interpretations. ${ }^{8}$ In the next subsection we clarify the role of these projections in relation to verbal inflection.

(7) a. Ted should have been being trained by a lion tamer.

b.

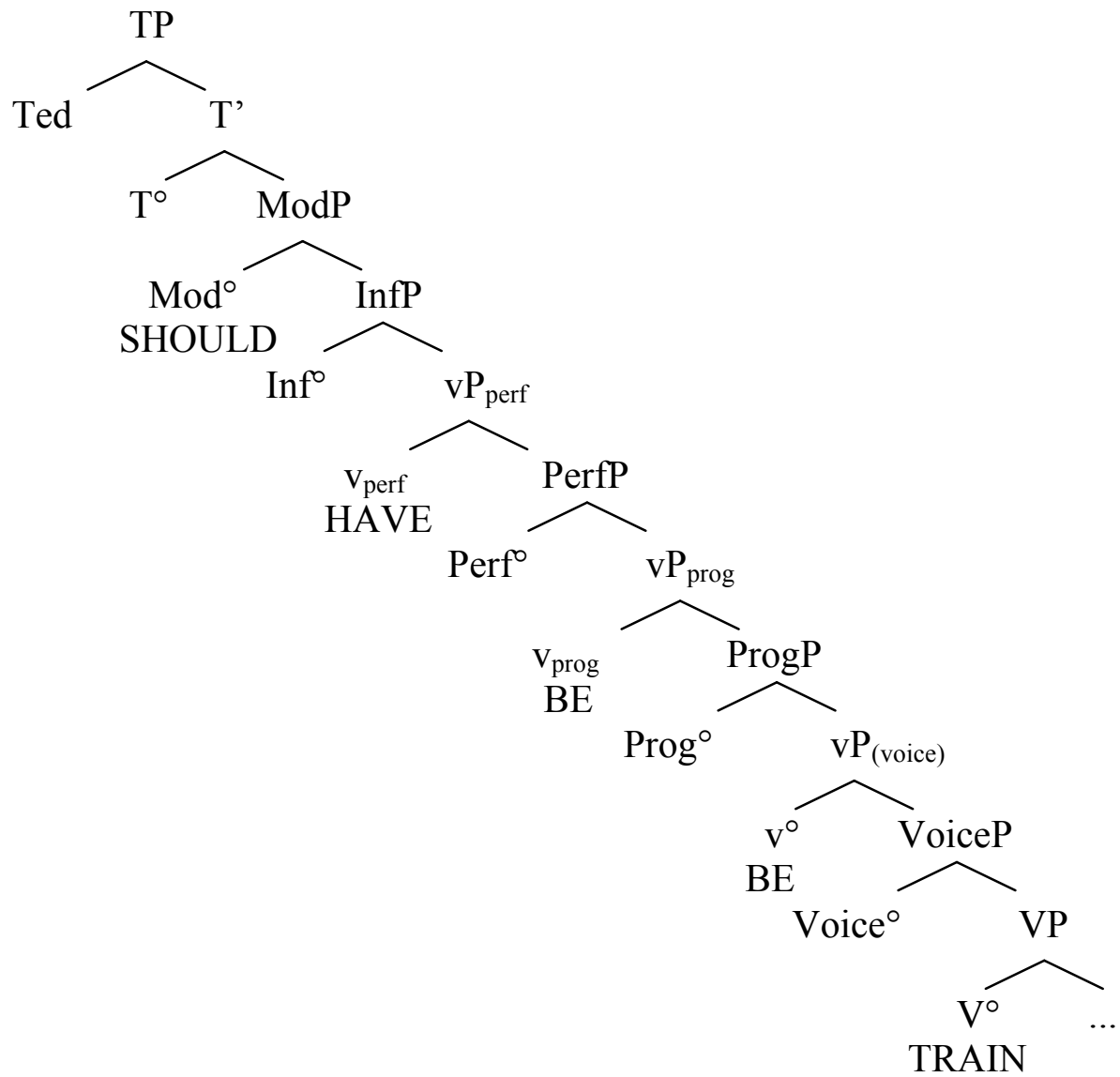

Since they are in complimentary distribution, we assume that passive be and copular be are both base-generated in the lowest vP shell which - following our notation - could also be labelled vP $\mathrm{P}_{\text {voice }}$ (see Baker 1997; Eide and Åfarli 1997; Bowers 2002; Bošković 2004, to

\footnotetext{
${ }^{8}$ In other words, neither the auxiliaries themselves, nor the vP shells they head are where the aspectual interpretation is encoded. This differs from the modal layer, because there it is the modal itself, in $\mathrm{Mod}^{\circ}$, that triggers the modal meaning, and not the InfP selected by it. This is not a crucial aspect of our analysis, however.
} 
appear; Bjorkman 2011; Harwood 2011, 2012). VoiceP is situated below this, encoding the passive/active status of the clause. ${ }^{9}$

We assume a 'What You See Is What You Get' approach (WYSIWYG) to the English auxiliary/aspectual system in that the aforementioned functional projections are only present in the underlying derivation if the relevant aspectual meaning is expressed in the clause. ${ }^{10}$ Since auxiliaries are closely tied to the aspectual inflections they trigger, in the sense that when you get one, you always get the other, we assume that if a certain aspectual projection is absent from the derivation, so is the vP shell introducing it, and vice versa.

\subsection{Verbal inflections}

With respect to the question of how verb forms acquire their inflections, we adopt Chomsky's (1993) and Lasnik's (1995b) approaches to the inflectional system. We claim, as per Chomsky (1993) and Lasnik (1995b), that English auxiliaries enter the derivation already inflected, but bearing uninterpretable inflectional features. These features need checking against the relevant inflectional head $\mathrm{T}^{\circ}$, $\operatorname{Inf}^{\circ}, \operatorname{Perf}^{\circ}$ or $\operatorname{Prog}^{\circ}$ carrying a matching interpretable inflectional feature. If the auxiliary fails to check its feature, the derivation crashes. Moreover, we take this checking of inflectional features to cause auxiliaries to overtly raise to the relevant inflectional head. ${ }^{11}$

\footnotetext{
${ }^{9}$ The analysis does not hinge upon the assumption that passive and copular BE are merged in the same position. It is entirely possible to have a slightly different structure, with, for instance, a separate $\mathrm{vP}_{\text {voice }}$ and VoiceP for the passive auxiliary and have copular BE introduced in vP proper, dominating VP.

${ }^{10}$ This does not imply that a clause without passive or copular BE automatically lacks a vP. The lowest vP is still present in transitive and unergative clauses to introduce the external argument, as per Chomsky (1995) and Kratzer (1996). In the structure suggested in the previous footnote this would mean that $\mathrm{vP}_{\text {voice }}$ could potentially be absent, but the vP in which copular BE can be introduced is always present, even without copular BE.

${ }^{11}$ It is because of auxiliary raising that we adopt a structure with split aspectual layers in which auxiliaries are merged into their own vP shells. If auxiliaries were merged directly into the heads of their aspectual projections, head movement constraint/locality condition violations would arise (Travis 1984; Chomsky 1986; Baker 1988; Rizzi 1990). That is, auxiliaries, in their quest to have their inflectional features checked, would inadvertently raise into higher aspectual heads, which are, however, already filled by either a higher auxiliary, or, at the very
} 
Concretely, finite auxiliaries are merged bearing a $[u \mathrm{~T}]$ feature which causes them to raise to $\mathrm{T}^{\circ}$ to be checked against $\mathrm{T}^{\circ}$ 's interpretable feature. Infinitival have and be enter the derivation bearing $[u \mathrm{Inf}]$ and raise to $\operatorname{Inf}^{\circ}$ to be checked against $[i \operatorname{Inf}]$. Been bears a $[u$ Perf] feature and raises to Perf ${ }^{\circ}$ to be checked against [iPerf]. Finally, being bears a [ $u$ Prog] feature which must raise and check against $\operatorname{Prog}^{\circ}$ 's $[i \operatorname{Prog}] .{ }^{12}$ This is illustrated in (8): $:^{13}$

least, a trace of that auxiliary, causing a locality violation. In order to prevent this, we merge auxiliaries into their own vP shells, leaving the head of the aspectual projection itself free for another auxiliary to raise into. Of course, if auxiliary raising can be reconciled with a structure without split layers, this would be preferred.

12 A potential issue for this approach is the reduplication of information: the auxiliary enters the derivation inflected, but still bears an uninterpretable feature which requires checking in order to license this form. This is a problem for any account that uses uninterpretable features, and we have no alternative for this. A possible solution is Late Insertion, where the auxiliaries enter the derivation as a bundle of abstract features, and the lexical items are inserted after syntax, as in Roberts (1998).

${ }^{13} \mathrm{We}$ take this raising and checking of auxiliaries to take place in a manner consistent with Bošković's (2007) theory of foot-driven movement. Under this approach, raising is triggered by an uninterpretable feature on the moving item, whilst maintaining the requirement of c-command on Agree. We refer the interested reader to Bošković's paper for an understanding of exactly how this can occur under current Minimalist assumptions.

A number of authors (Adger 2003; Bjorkman 2011; Wurmbrand to appear) alternatively argue that the checking of the auxiliaries' inflectional features takes place via Reverse Agree (see Aelbrecht 2010; Baker 2008; Haegeman \& Lohndal 2010; Merchant 2011; Wurmbrand 2011; Zeijlstra 2008, 2010 for discussion and application of this mechanism in other domains), with auxiliaries and their uninterpretable features remaining in their base positions. This predicts, however, that auxiliary distribution should be determined by auxiliary type, i.e., whether the auxiliary is progressive, passive etc. in origin, and not by morphological form. However, due to the distributional differences exhibited between be/been on the one hand, and being on the other, as observed in VPE phenomena as well as VP fronting phenomena (see section 5), we take auxiliary distribution to in fact be determined by morphological form and not by auxiliary type. This is correctly predicted by the auxiliary raising analyses as per Chomsky (1993) and Lasnik (1995b). For reasons of space we cannot go into all of the arguments in favour of non-finite auxiliary raising (and contra Reverse Agree approaches), but see Roberts (1998) and Harwood (2013). 
(8)

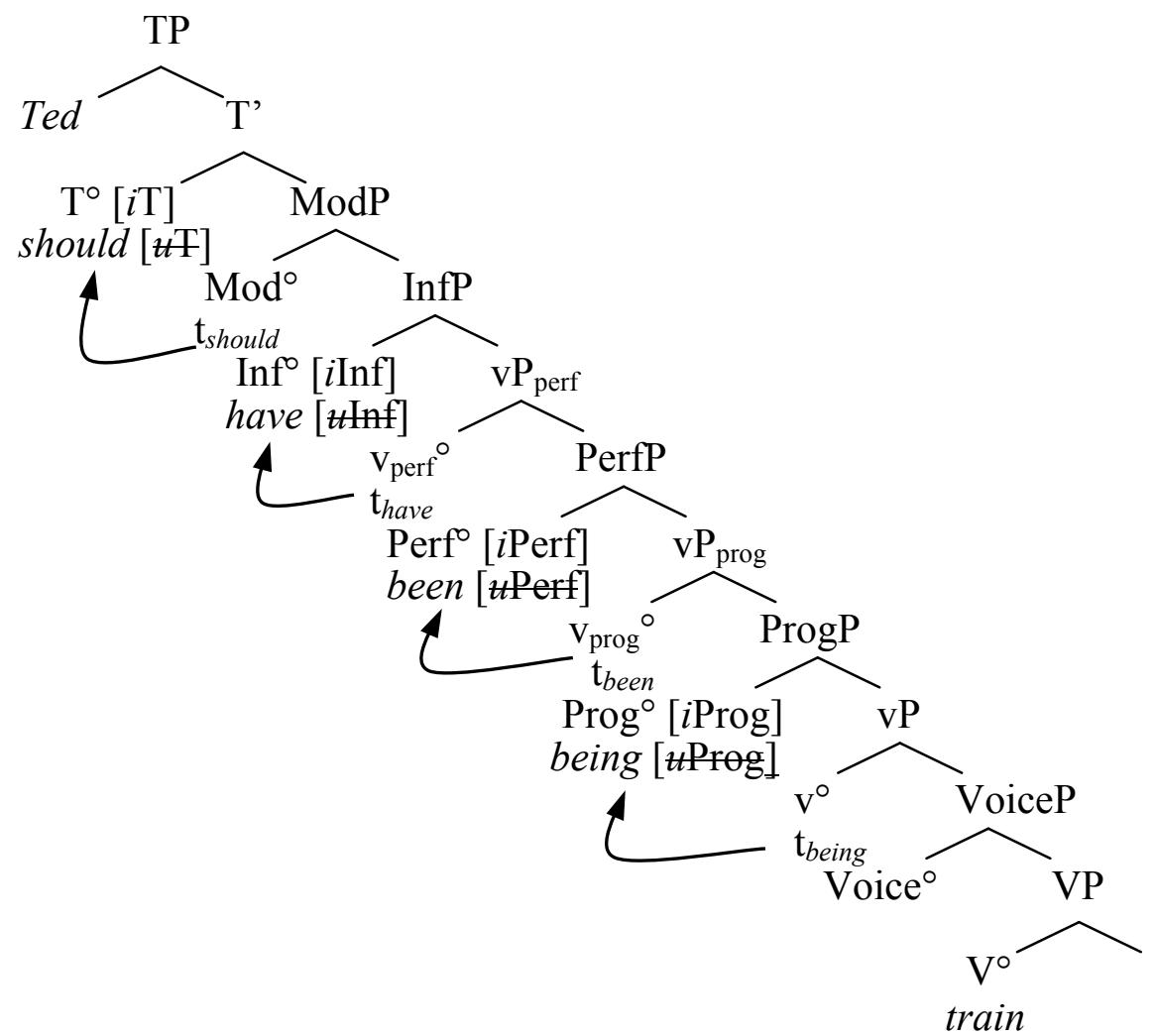

For completeness' sake we outline how the lexical verb behaves in this system. We assume, following Lasnik (1995b) and Baker (2003), that lexical verbs, unlike auxiliaries, enter the derivation uninflected and, consequently, without any kind of inflectional features. The lexical verb therefore stays in situ and receives its inflections via linearisation at PF. ${ }^{14}$

Finally, we take the overt raising of auxiliaries for reasons of feature checking to be a matter for PF rather than LF. This is assumed in Chomsky (1993), Chomsky (1995) and especially also Lasnik (1995b), who takes the features responsible for verbal inflection to "not [be] legitimate PF objects", which would cause a crash at PF in the case of non-raising and hence, non-checking, "even though LF requirements would be satisfied" (Lasnik 1995b: 256). This implies that the movement and checking of auxiliaries should be construed as licensing

\footnotetext{
${ }^{14}$ There are many ways in which one can implement the difference between auxiliaries and main verbs, and this is only one of them. Nothing hinges on the claim that lexical verbs receive their inflections through linearisation.
} 
of the auxiliary's form for PF reasons: if the feature is not checked overtly (in the syntax), it causes a crash at PF, though no such violation occurs at LF (see Lasnik 1995b). ${ }^{15}$

With these structures and implementations in mind, we proceed to section 3, which presents the first part of our approach: our view on the VP ellipsis site. We argue that the ellipsis site is as large as $\mathrm{vP}_{\text {prog }}$ (though no larger) when that projection is present, and in the absence of $\mathrm{vP}_{\text {prog }}$ the ellipsis site corresponds to the highest projection below this, namely $\mathrm{vP}$. In order to explain the contrast between be/been, being and have in (6), we propose in section 4 that the forms be and been optionally raise from their base positions contained within the ellipsis site to positions outside of it, and that they thus optionally escape ellipsis, whereas the auxiliary being never raises high enough to escape. Have, on the other hand, is base-generated outside of the ellipsis site and so never has the opportunity to be elided.

Our analysis is extended to other related phenomena, namely VP fronting, tag questions, pseudo-clefting and predicate inversion in section 5. Finally, we speculate in section 6 that the target of VPE is in fact the highest predicative projection and present a formalisation for this approach. In other words, VPE is in fact predicate ellipsis.

\section{The analysis, part I: a well-defined ellipsis site}

Standardly, as the label suggests, VPE has been assumed to involve non-pronunciation of the verb phrase. Over the course of the last ten to twenty years, however, there has been some debate as to how big this missing verb phrase is exactly. Many accounts of VPE have claimed that the ellipsis site is either VP, vP or VoiceP (Lasnik 1995a; Johnson 2001, 2004; Merchant

\footnotetext{
${ }^{15}$ Although the term 'uninterpretable' immediately conjures up a link with LF, we use it, for lack of a better one, for features that need checking in order to avoid a PF crash. It is of course possible that the uninterpretable inflectional features on the auxiliaries we propose must be checked at LF too, but this would inevitably take place in the covert (LF branch) part of the syntactic component. However, whether the uninterpretable features on auxiliaries are a concern for LF or not is relatively immaterial. The crucial point is that (overt) movement of the auxiliary is a concern for PF, not LF. See also Zeijlstra (2011) for a discussion on the nature of features.
} 
2001, 2008a,b, 2013; Gengel 2007; Aelbrecht 2010). We argue, contrary to more standard assumptions, that VPE targets a constituent which is larger than just VP, VoiceP or vP. According to us, when the progressive aspectual layer is projected, VPE elides as much as $\mathrm{vP}_{\text {prog}}$, containing progressive $\mathrm{BE}$ (though nothing larger). This implies that the ellipsis site also contains ProgP, with the progressive inflectional feature. In the absence of the progressive aspectual layer however, VPE targets $\mathrm{vP}$, as standardly assumed. ${ }^{16}$

In this section we provide evidence for our claim that the progressive layer is included in the ellipsis site. This evidence comes from empirical data concerning ellipsis of auxiliaries: only auxiliaries which are merged inside the ellipsis site can ever be elided. We have seen that some auxiliaries are always elided under VPE, some never, and some only optionally. Several accounts have already been proposed to account for this pattern (see Akmajian \& Wasow 1975; Akmajian, Steele \& Wasow 1979; Sag 1976, or more recently Bošković to appear; Sailor 2012; Thoms 2012), but, irrespective of the analysis one chooses, the consensus about auxiliary deletion is that an auxiliary can only be elided if it is at some point in the derivation included in the ellipsis site. We show that auxiliaries generated within and below $\mathrm{vP}_{\text {prog }}$ can be elided by VPE, whilst those generated above it cannot be. Consequently, this implies that the ellipsis site is as large as $\mathrm{vP}_{\text {prog. }}$. We first illustrate that all the different types of $\mathrm{BE}$ (copular, passive and progressive) can be elided, and then show that HAVE can never be deleted, even though this has been contested in the literature.

\subsection{Instances of $\mathrm{BE}$ can be elided}

The auxiliary BE can occur in several morphological forms (been, be, being or finite forms), but these forms can also have different origins: BE can be copular, passive or progressive.

\footnotetext{
${ }^{16}$ We come back to the question of what determines the size of the ellipsis site in section 6 .
} 
The first two instances are in complementary distribution and, as we indicated in section 0 , we take them to be base-generated in the little $v$ head. Progressive BE can cooccur with passive or copular BE and is thus base-generated in a position higher than $v$, namely $\mathrm{v}_{\text {prog. }}$.

In order to determine which projections are included in the VP ellipsis site, we need to test which auxiliaries can be deleted. If an auxiliary can be elided, its base position (at least) is part of the ellipsis site. We show that all instances of BE - copular, passive and progressive can be elided, so VPE must (at least) target $\mathrm{vP}_{\text {prog. }}$. First, we illustrate that copular BE can be elided, whether it occurs as be, been or being, see (9). The first two forms are deleted optionally, and being is elided obligatorily. ${ }^{17}$ Second, passive BE can be deleted too, see (10).

(9) a. Ted has been in the garden, and Robin has (been), too.

b. Ted will be in the garden, and Robin will (be), too.

c. Ted was being noisy, and Robin was (*being), too.

(10) a. Ted has been arrested, and Barney has (been), too.

b. Ted will be arrested, and Barney will (be), too.

c. Ted was being arrested at that time, and Barney was (*being), too.

Progressive BE poses more of a problem. It seems like it can be elided when it occurs as be or been (progressive BE never occurs as being):

(11) a. Ted has been questioning our motives, but Robin hasn't (been).

b. Ted will be questioning our motives, but Robin won't (be).

\footnotetext{
${ }^{17}$ The issue of being is slightly more complicated than we present it here. We come back to this in section 7.
} 
However, one could argue that the presence of progressive BE in the antecedent does not necessarily imply the presence of the progressive in the ellipsis site. In other words, when the progressive auxiliary is elided, the sentences in (11) could allow for a mismatch reading where the ellipsis clause does not actually contain progressive aspect, but is instead interpreted as in (12):

(12) a. ...but Robin hasn't [questioned our motives].

b. ...but Robin won't [question our motives].

Sailor (2012) has even claimed that in such cases, an interpretation with the progressive is ungrammatical. From his claim it would follow that progressive BE is never elided. Because these interpretation-based arguments are hard to convincingly draw conclusions from, however, it is necessary to find contexts showing whether the progressive auxiliary can genuinely be elided by VPE. Two such contexts are existential constructions and idiomatic expressions. Using these contexts we show that progressive BE can be (optionally) elided.

We look at existential constructions first. English existentials display certain aspectual restrictions (Milsark 1974; Aissen 1975; Deal 2009; Harwood 2011): unaccusative verbs can occur in existentials with all kinds of aspect ((13)), but unergative verbs are only allowed with the progressive, $\mathrm{cf} .(14) .^{18}$

(13) a. There arrived a crocodile in the mail.

[unaccusative]

b. There has arrived a crocodile in the mail.

c. There will be a crocodile arriving in the mail.

\footnotetext{
18 Transitive and ditransitive existentials are subject to the same aspectual restrictions. See Deal (2009) and Harwood (2011) for an explanation of this restriction.
} 
$(14)$

a. * There danced a crocodile in the garden.

[unergative]

b. * There has danced a crocodile in the garden.

c. There was a crocodile dancing in the garden.

This means that when ellipsis is applied to an unergative existential, we can be certain as to the presence of progressive aspect in the ellipsis site. ${ }^{19}$ It turns out that all our informants unanimously accept deletion of progressive BE in this context:

(15) a. He said there will be a crocodile dancing in the garden, but there won't (be).

b. He said there had been a crocodile dancing in the garden, but in fact there hadn't (been).

\footnotetext{
${ }^{19}$ It has been argued in the literature (Williams 1984; McNally 1992; Moro 1997; Law 1999) that all the material following the associate in progressive existentials is actually contained inside a reduced relative clause (RRC) and is not part of the main clause (cf. (i)).
}

(i) [TP There was [DP a crocodile [RRC (who was) dancing in the garden]]]

If this is correct, we cannot use existentials to make any claims about VPE in main clauses: the supposed optional ellipsis of progressive BE that we have uncovered would simply be optional ellipsis of copular BE.

However, although an RRC structure for existentials is possible, transitive and unergative existentials may also behave as mono-clausal constructions, and moreover, so can the cases involving ellipsis. This is evidenced by the fact that these progressive existentials exhibit properties which RRCs do not. For instance, Deal (2009) has observed that whilst reduced relatives must precede full relatives, no such restriction occurs in existentials:

(ii) a. The teacher scolded [the student [laughing in the hall] [who was wearing a cap]].

b. * The teacher scolded [the student [who was wearing a cap] [laughing in the hall]].

c. There is a man <laughing in the hall $>$ [who's wearing a cap] $<$ laughing in the hall $>$.

Therefore existentials have an underlying structure available to them that does not involve an RRC, but a monoclausal structure. Transferring this observation to progressive existentials involving VPE, the same pattern holds:

(iii) John said there had been a man who was wearing a cap laughing in the hall, but in fact there hadn't (been) [a man who was wearing a cap laughing in the hall].

Other differences between progressive existentials and RRCs involve idioms (Chomsky 2001) and eventive copular constructions (Milsark 1974, Caponigro \& Schutze 2003 and Rezac 2006), indicating that progressive existentials can not only be formed from RRCs, but also have an underlyingly mono-clausal structure available to them. In the contexts presented in these works as well, VPE can be applied, suggesting that our observations regarding ellipsis of the progressive auxiliary in existentials are genuine. That is, (15) is a genuine case of main clause VPE with the progressive auxiliary being optionally included within the ellipsis site. 
In other words, (14) indicates that an existential with an unergative verb cannot occur without the progressive. This implies that the hearer cannot interpret (15) without the progressive and that progressive BE is genuinely included in the ellipsis site, just like passive and copular BE.

A second context that can show whether progressive BE can genuinely be elided involves idiomatic expressions. There are certain idioms which depend upon progressive aspect: only the sentence in (16)a with the progressive aspect has the idiomatic reading.

(16) a. Bob is pushing up daisies. = Bob is dead.

b. \# Bob pushed up daisies. $\quad$ \# Bob died/was dead.

c. \# Bob will push up daisies. $\quad \neq$ Bob will die/will be dead.

d. \# Bob has pushed up daisies. $\quad \neq$ Bob has died/has been dead.

If VPE is applied to such an idiom and the idiomatic interpretation is retained even without the overt presence of the progressive auxiliary, this implies that progressive aspect and, crucially, the progressive auxiliary, are present in the derivation. All our informants still interpreted (17) as an idiom, which means they accept ellipsis of the progressive auxiliary:

(17) a. Lola told us that Bob has been pushing up daisies for a while now, and indeed he has (been).

b. Lola told us that Bob might be pushing up daisies by now, and indeed he might (be).

Irrespective of how one accounts for the optional ellipsis of be/been, whether it be optional auxiliary raising (see section 4.2), or optional extension of the ellipsis site (Akmajian, Steele \& Wasow 1979; Bošković to appear), the consensus is that for an auxiliary to be elided, it 
must be included in the ellipsis site at some point in the derivation. Thus, for the progressive auxiliary to be optionally elided in (15) and (17), the ellipsis site must be as large as $\mathrm{vP}_{\text {prog. }}$.

\subsection{HAVE cannot be elided}

Akmajian and Wasow (1975) and Sag (1976) noted that the non-finite perfect auxiliary have is never elided. However, there has been some debate about this claim in the literature, and it is only fair that we explore this issue properly before building our analysis.

Although many authors agree with the original pattern concerning have (see Zagona 1988; Lobeck 1987; Johnson 2001; Bošković to appear; Sailor 2009, 2012; Wurmbrand 2012), some linguists argue that this is not true, and that perfect have can indeed be elided (Akmajian, Steele \& Wasow 1979 and Thoms 2011, 2012). This is evidenced by the following sentence in which have appears to have been elided:

(18) John might have called, and Bill might, too.

(Wurmbrand 2012:10)

However, Johnson (2001) and Wurmbrand (2012) contest the claim that have can be elided, and argue that what causes the acceptability of this sentence is the fact that there is a mismatch reading available which lacks perfect aspect altogether. According to them, the ellipsis site is not [have called], but [ealt], which in the right context will be interpreted appropriately by the hearer. Wurmbrand (2012) rules out this interfering mismatch interpretation by using conflicting time specifications. In these instances, her informants judged ellipsis of have to be unacceptable (Wurmbrand 2012: 10, example (36)b'):

(19) * John might have called yesterday, and Bill might, two days ago. 
This therefore constitutes some evidence towards the claim that the perfect auxiliary cannot be elided. In what follows, we look at further contexts which can show us whether the perfect auxiliary can genuinely be elided or not, namely fixed expressions, identity requirements and before-clauses. We conclude from these that have cannot be elided, conforming with the original findings, although we do not exclude idiolectal or dialectal variation.

First, we discuss fixed expressions. There are expressions that are dependent upon perfect aspect, such as in (20). Without the perfect aspect, these sentences are unacceptable.
a. Ted has been to Rome.
c. * Ted will be to Rome.
b. * Ted is to Rome.
d. * Ted is being to Rome.

If VPE is applied to these cases, no mismatch interpretation without the perfect aspect is available. Thus, this expression provides us with a test context to determine whether have can be elided or not. As it turns out, $80 \%$ of our (British English) informants reject (21) when perfect have is included in the ellipsis. ${ }^{20}$ This suggests that have cannot be deleted under VPE.

(21) This time next year Ted will have been to Rome, and Barney will *(have), as well.

Another context, involving identity requirements, provides even clearer results regarding ellipsis of have. It has been noted that auxiliaries in English can only be elided

\footnotetext{
${ }^{20}$ We tested these sentences with 20 British English speakers, from all over Britain. Even though $80 \%$ of these speakers reject deletion of have, it is true that some speakers still accepted it. The editor and one of the reviewers, as well as 10 family members and friends of the reviewer, were also fine with have deletion. At the moment we have no means of explaining these contradicting results, and suspect it is due to some dialectal or idiolectal variation. We note that, from the people we tested, the few speakers who did accept deletion of have did not come from the same geographical area. Moreover, the next context we use to test have deletion gives us clearer results: none of our informants accepted deletion of have in that context, not even the speakers who were fine with the deletion in the fixed expressions.
} 
when they have a formally identical antecedent (Warner 1986; Lasnik 1995b; Johnson 2001). This is illustrated in (22) for be and been: if the antecedent contains the auxiliary in a different morphological form, the normally optional ellipsis of be and been becomes impossible. If the antecedent contains the same form, on the other hand, ellipsis is fine.

(22) a. Sue has been eaten by cannibals, and Rob might*(be), too.

b. Sue will be eaten by cannibals, and Rob will (be), too.

c. Sue was eaten by cannibals after Rob had *(been).

d. Sue has been eaten by cannibals, and Rob has (been), too.

This implies that in the following sentence, the passive auxiliary in the elided constituent must be identical to its antecedent form been, in order for the sentence to be grammatical:

(23) Bob might have been fired, and Morag might have (been) fired, too.

Thus, the elided passive auxiliary depends on perfect aspect in order to be realised as been and fulfil the identity requirement. If perfect aspect were absent from the second conjunct, the elided auxiliary would be realised as be, which is non-identical to its antecedent. It would not be recoverable, and therefore lead to illicitness. In short, this gives us another context that depends on perfect aspect. No aspectual mismatch interpretation is available to mask potential ellipsis of have. As it turns out, all our informants rejected deletion of have in this context. ${ }^{21}$

\footnotetext{
${ }^{21}$ Note that the ellipsis site can be interpreted in one of two ways: the hearer can interpret the ellipsis site as containing have (see (i)), or they can accommodate with a mismatch interpretation without have (as in (ii)):

(i) * Ted might have been fired, and Barney might [have been fired], too.

(ii) $\quad *$ Ted might have been fired, and Barney might [be fired], too.

Both options lead to ungrammaticality: option 2 is illicit because of the identity requirement on be (i.e., there is no be present in the antecedent, so be cannot be elided), and option 1 is unacceptable because deletion of have is disallowed under VPE. Either way, the data demonstrates that have cannot be included in the ellipsis site.
} 
(24) * Ted might have been fired, and Barney might, too.

A final context, taken from Sailor (2012), involves temporal clauses that are sensitive to aspect, such as before-clauses. As Sailor observes, these result in ungrammaticality if have is included in the ellipsis site, and without have the sentence does not get a sensible reading:

(25) Mary could have studied harder for the exam. Before finally taking it yesterday...
a. ...she really should have.
b. *...she really should.

(Sailor 2012, his (36))

Summing up, although there might be some dialectal/idiolectal variation regarding deletion of perfect have, we are fairly confident in claiming that have generally cannot be elided.

We have shown in section 3.1 that all instances of BE, on the other hand, can be elided, whether it is copular, passive or progressive. Recall that for any auxiliary to be able to undergo ellipsis, it has to have been included in the ellipsis site at one point in the derivation, irrespective of the exact analysis one chooses. Therefore, in order for as much as the progressive auxiliary to be elidable, but nothing more, VP ellipsis in English must target as much as $\mathrm{vP}_{\text {prog, }}$, and not only $\mathrm{vP}$ or $\mathrm{VP}$. If however, the progressive aspectual layer is absent from the derivation, then we assume VPE to target vP. Next, we show how the claims made so far capture the deletion paradigm.

\section{The analysis, part II: the auxiliary paradigm}


The pattern our proposal tries to capture is summarised in (6), repeated as (26): the finite auxiliary and non-finite have always escape ellipsis, be and been are optionally deleted and both being and the lexical verb are always elided.

(26)

\begin{tabular}{|l|l|l|l|l|l|l|}
\hline & modal/finite aux & have & be & been & being & lexical verb \\
\hline elided & $*$ & $*$ & $\checkmark$ & $\checkmark$ & $\checkmark$ & $\checkmark$ \\
\hline remaining & $\checkmark$ & $\checkmark$ & $\checkmark$ & $\checkmark$ & $*$ & $*$ \\
\hline
\end{tabular}

Table 1: Deletion of verbal elements in VP ellipsis

Recall furthermore that we take the ellipsis site to be $\mathrm{vP}_{\text {prog }}$, and that auxiliaries raise to check their inflectional PF features against the relevant aspectual head.

We first tackle the easiest patterns: the auxiliaries that are always overt or always elided, namely have and being (and the finite auxiliary and the lexical verb), respectively. Section 4.2 turns to the optionally deleted auxiliaries be and been.

\subsection{Being and have}

The first piece of data our analysis wishes to capture is the obligatory deletion of being:

(27) a. Ted was being eaten by a gorilla and Robin was (*being) too.

b. Ted is being difficult and Robin is (*being) too.

Under our view on verbal inflections, being raises from $v^{\circ}$ to $\operatorname{Prog}^{\circ}$ to check its inflectional feature, as in (28). This landing site of being is still included in the $\mathrm{vP}_{\text {prog }}$ ellipsis site, 
meaning being never escapes ellipsis. The illicit ellipsis of non-finite perfect have can be explained as the opposite of this: both the landing site and - crucially - the base position of have are outside of the $\mathrm{v}_{\text {prog }}$ ellipsis site and therefore have obligatorily escapes ellipsis.

(28)

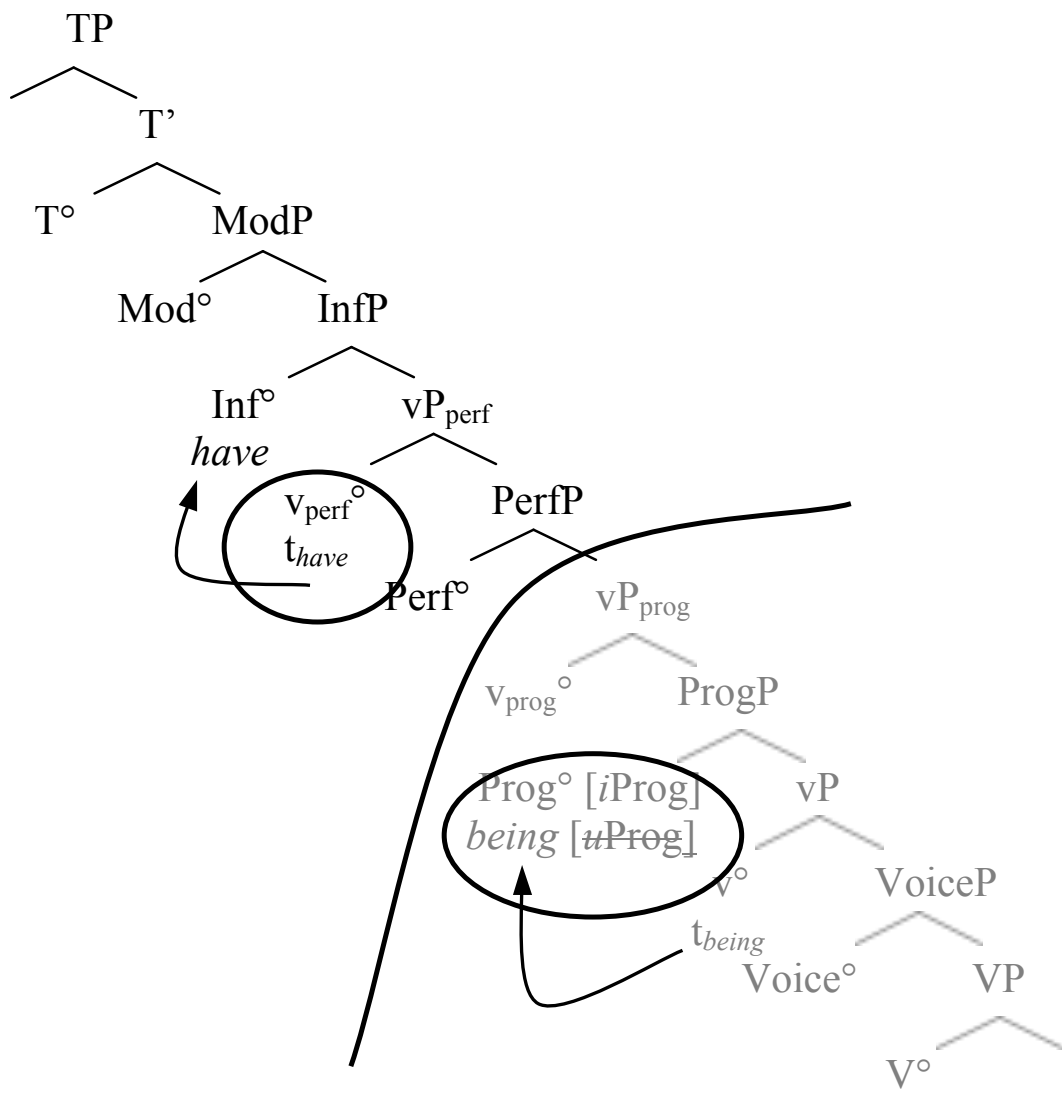

The lexical verb in English never raises for inflection if we follow Lasnik (1995b), so it never moves out of the ellipsis site and is always elided. It should also be clear by now why modals and the finite perfect auxiliary HAVE are never elided: both the base position and the landing site are outside of the ellipsis site. Finite BE, however, raises a number of questions. We return to finite $\mathrm{BE}$ in section 7 , where we deal with some other remaining issues too.

\subsection{Be/been}


We have seen earlier that being is obligatorily elided, while have never is. Be and been, on the other hand, are optionally elided. The relevant data are repeated in (29).

(29) a. Ted has been eating a sandwich and Robin has (been) [eating a ...], too.

b. Ted will be eating a sandwich and Robin will (be) [eating a ...], too.

Our approach, in a nutshell, is that optional ellipsis of be/been results from optional raising of these auxiliaries out of the ellipsis site. In the case of raising, the auxiliaries move out of the ellipsis site, surviving ellipsis, and have their inflectional features checked against the relevant aspectual heads. In the case of non-raising, the auxiliaries remain in the ellipsis site and ellipsis deletes the unchecked inflectional features with the auxiliaries. In other words, there are two derivational paths available, raising and non-raising, both of which result in a grammatical sentence, and so give rise to optionality.

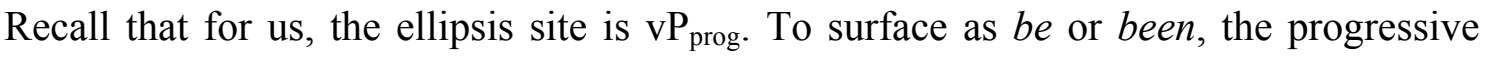
auxiliary - or passive or copular - should raise to the respective inflectional heads Inf $^{\circ}$ or Perf $^{\circ}$ in order to check its inflectional feature. This causes it to raise out of the ellipsis site, surviving ellipsis.

However, this raising does not have to occur under ellipsis. When be and been are elided, it is because they have failed to raise out of the ellipsis site. This implies that the unraised auxiliaries have not had a chance to check their inflectional features on Inf ${ }^{\circ}$ or Perf ${ }^{\circ}$. Still bearing unchecked features, our derivation would be in danger of crashing at PF. However, ellipsis saves the derivation from crashing: if we delete the material in the ellipsis site, the offending auxiliary, including its unchecked feature, is elided too. Consequently, it is no longer a problem for PF, and the derivation is rescued. The structures in (30)b and (30)c illustrate what happens in the sentence in (30)a with optional deletion of be. 
(30) a. Ted will be eating a sandwich and Robin will (be), too.

b. Deletion of be

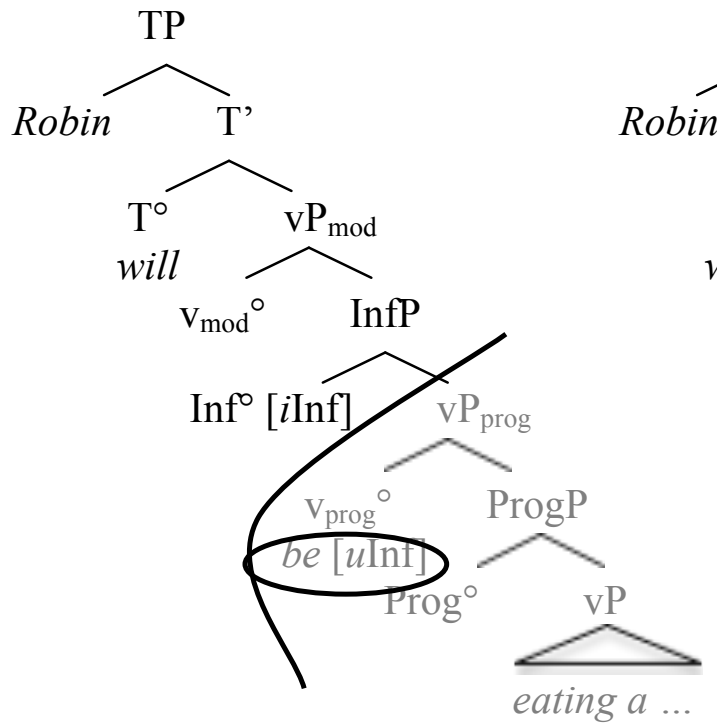

c. Non-deletion of be

$\mathrm{TP}$<smiles>[Te]C[Te]</smiles>

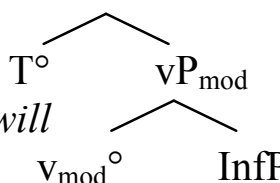

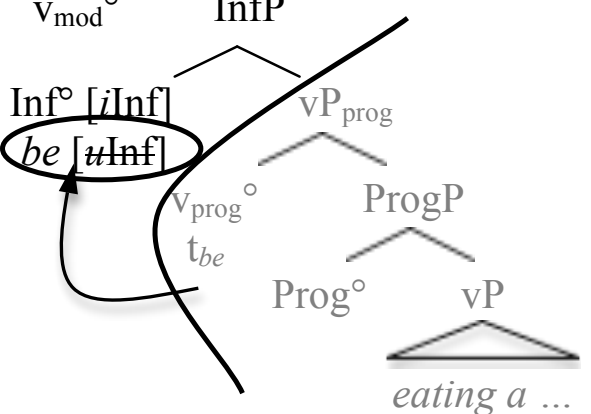

This proposal sits in line with a number of rescue by PF-deletion analyses of various other phenomena which have been proposed by several authors (Ross 1969; Lasnik 1999, 2001; Merchant 2001; Müller 2011). ${ }^{22}$

Recapitulating, we propose that the ellipsis site is maximally $\mathrm{vP}_{\text {prog, }}$, which includes the base position of all instances of BE (progressive, passive and copular). Being never raises beyond $\operatorname{Prog}^{\circ}$, so is always contained within the ellipsis site, explaining why this form is always elided under VPE. HAVE and modals on the other hand, are always merged outside of the ellipsis site, and can never be elided. Be and been are merged within the $\mathrm{vP}_{\text {prog }}$ ellipsis site, but raise out of it to check their uninterpretable inflectional features. This captures their

\footnotetext{
${ }^{22}$ An alternative analysis from the one we propose would be one inspired by Lasnik's (2001) approach to pseudo-gapping: the uninterpretable feature could also be checked by feature movement only, leaving the auxiliary behind. In non-elliptical sentences, feature movement is not an option, as this turns the auxiliary into a deficient PF object, and causes the derivation to crash. Ellipsis, on the other hand, avoids such a violation by removing the auxiliary. Therefore, no crash occurs at PF.

An important difference between our proposal and Lasnik's approach is that for us, both options of raising and non-raising of the auxiliary are equally possible in ellipsis contexts, which results in the optionality. For Lasnik, the feature movement that becomes possible under ellipsis turns out to be the only option, because feature movement is less costly for the derivation than actual verb movement. Hence, our approach towards auxiliaries is incompatible with Lasnik's view on Pseudogapping.
} 
optional deletion: if they raise out of the ellipsis site to check their features, they survive ellipsis, and if they remain in the ellipsis site, their uninterpretable features are elided along with them, preventing a derivational crash at $\mathrm{PF}^{23}$

This implies, however, that the option of not raising is only possible for auxiliaries under ellipsis. We predict that raising is obligatory in all other contexts since no ellipsis occurs to delete the unchecked PF features on the auxiliary otherwise. As we show in section 5, this prediction is borne out, where we extend our analysis to VP fronting and other related phenomena. Before we show how exactly these other contexts are captured, we present some other recent accounts for the optional auxiliary deletion, and outline some of their problems.

\subsection{Previous accounts for the auxiliary deletion pattern}

The majority of the ellipsis literature avoids the behaviour of non-finite auxiliaries under English VPE, particularly regarding the optional deletion of be and been. Recently however, a number of proposals have been made to account for the English auxiliary ellipsis paradigm. In what follows, we review these accounts. We first discuss Bošković (to appear), and present its advantages and drawbacks, and then move on to Thoms (2012) and Sailor (2012).

\subsubsection{Bošković (to appear)}

Our proposal is not the only option to capture the optional deletion of be and been. One possible solution, instead of having a fixed ellipsis site and optional raising out of it, is to say that the size of the ellipsis site can fluctuate, in the sense that the ellipsis site normally does

\footnotetext{
23 As an anonymous reviewer pointed out, this approach might be hard to reconcile with analyses such as Tancredi (1992), Gardent (2000) and Hardt (2005), for instance, which unify ellipsis and deaccenting.
} 
not contain be or been, but can be optionally extended to included them (or vice versa). ${ }^{24}$ Bošković's (to appear) account uses this tactic, as does the original proposal by Akmajian, Steele \& Wasow (1979).

Bošković (to appear) makes a number of assumptions as to the structure of the middle field which are highly similar to our own. He essentially assumes the same functional hierarchy that we established in (7), and the same analysis with regards to auxiliary raising (though he motivates this through a morphological requirement rather than through feature checking). He also takes a WYSIWYG approach.

Bošković assumes a degree of optionality with respect to what VPE can target. That is, he claims VPE can target the highest projection in the extended domain of the lexical verb, or the projection just below it. In the absence of any aspectual projections, he takes VPE to target either vP or VP (there is no VoiceP intervening between $\mathrm{vP}$ and VP in his system). Following Lasnik (1999), Bošković claims that the lexical verb does not raise out of its base position of $\mathrm{V}^{\circ}$ in ellipsis contexts. Therefore the lexical verb is obligatorily elided under VPE.

In the presence of progressive aspect, on the other hand, Bošković assumes VPE to target either ProgP, or vP below it. Note that the $\mathrm{vP}_{\text {prog }}$ shell above ProgP is not targeted by VPE in this instance. This is the first problem with his account: vP shells also form part of the extended projection under Bošković's assumptions, and in the absence of any higher aspectual material, $\mathrm{vP}_{\text {prog }}$ would constitute the highest projection in the extended domain of the lexical verb. So it is a mystery why the $\mathrm{vP}_{\text {prog }}$ shell should not be targeted by VPE. ${ }^{25}$

\footnotetext{
${ }^{24}$ Of course, the 'fixedness' of our ellipsis site is not as rigid as it seems: as we have claimed, our ellipsis site differs depending on which projections are present in the structure. But this variation does not occur in the derivation of a single sentence in order to capture the optionality of be/been deletion.

${ }^{25}$ Bošković takes a phasal approach to ellipsis as per Holmberg (2001) and Gengel (2007) in which the ellipsis site is either the complement of the phase head or the entire phase itself. He furthermore proposes a dynamic approach to phases in which the highest phrase in the extended projection of the verb is the clause internal phase. This explains how aspectual projections are able to be targeted by VPE under a system in which ellipsis is constrained by phases. However, the issue of VPE targeting an AspectP, but not the vP shell above it, remains. Whilst we are sympathetic to the idea that projections other than just vP and CP may constitute phases, the
} 
In order to account for the obligatory ellipsis of being, Bošković claims, following Akmajian \& Wasow (1975), Akmajian, Steele \& Wasow (1979), Iwakura (1977), Lobeck (1987), Bošković (2004) and Thoms (2011), that being is the only auxiliary that does not raise for inflectional purposes and instead has its inflection lowered onto it in its $\mathrm{v}^{\circ}$ base position. The reason for this is clear: if being rose to $\operatorname{Prog}^{\circ}$ for inflectional purposes, it is predicted to only be optionally elided. In order for being to remain consistently in the ellipsis site, Bošković is forced to claim that being does not raise from its base position. However, there is no principled reason as to why being should be the only auxiliary not to raise.

In the presence of perfect aspect, which Bošković also assumes to constitute part of the extended projection of the lexical verb, VPE may target either PerfP, or the complement of PerfP ( $\mathrm{vP}_{\text {prog }}$ or $\mathrm{vP}$, depending on whether the progressive aspectual layer is present or not). Again, the $\mathrm{vP}_{\text {perf }}$ shell above PerfP is curiously not targeted by VPE. The optional deletion of been now falls out of this analysis: been raises for inflectional purposes to Perf ${ }^{\circ}$, which is optionally targeted by ellipsis.

The analysis raises problems, however, with respect to the optional ellipsis of be under similar mechanisms. Unfortunately, Bošković does not specifically discuss the optional ellipsis of be, but by extending the analysis he has made so far we can observe which data can and cannot be accounted for.

In the presence of the modal layer, Bošković allows for ellipsis to target either the complement of InfP, or InfP itself. This instantly explains the optional ellipsis of be: if we decide to elide the complement of InfP, $b e$ - surfacing in Inf $^{\circ}-$ survives ellipsis. If on the other hand, we elide InfP itself, $b e$ is contained within the ellipsis site and so is elided.

problem is that by allowing an AspectP to act as a phase and not the vP shell above it, we are separating aspects and their associated auxiliaries by a phasal boundary. As was stated earlier, auxiliaries are always closely tied to their aspectual forms: whenever $\mathrm{vP}_{\text {prog }}$ is present, so is $\mathrm{Prog} \mathrm{P}$, or whenever $\mathrm{vP}_{\text {perf }}$ is present, so is PerfP. It seems strange then that the auxiliary should be separated from its aspect by a phase boundary, as Bošković implies. 
This claim, however, raises a number of problems. First, what if non-finite have has risen to occupy Inf ${ }^{\circ}$ rather than $b e$ ? Should we not still expect ellipsis to target either the complement of Inf ${ }^{\circ}$, or InfP itself? In that case have is predicted to be optionally included in the ellipsis site, contrary to fact: Bošković (to appear) assumes infinitival have is never elided. Moreover, if in the presence of InfP the complement of $\operatorname{Inf}^{\circ}$ must always be elided under VPE, we should expect everything below the infinitival auxiliary to be obligatorily elided under ellipsis. Consider, however, (31), with non-finite have in Inf ${ }^{\circ}$, and been in Perf ${ }^{\circ}$, in the complement of Inf ${ }^{\circ}$. Here one incorrectly expects been to be obligatorily elided.

(31) John could have been defeated, and Peter could have (been) defeated too.

Bošković's analysis is reminiscent of an early generative approach by Akmajian, Steele \& Wasow (1979). For them the optional ellipsis of be/been is accounted for via optional extension of the ellipsis site to include the aspectual projections. Many of the arguments against Bošković's account can be extended to Akmajian, Steele \& Wasow’s (1979).

\subsubsection{Thoms (2012)}

Thoms (2012) takes a different approach to the ellipsis of being and the optional deletion of be and been: He argues that all auxiliaries check their inflectional features in their base positions via Reverse Agree (as per Bjorkman 2011), and that ellipsis is licensed by subsequent movement of the finite auxiliary to $\mathrm{T}^{\circ}$. Under Thom's analysis, everything in the complement of $\mathrm{T}^{\circ}$ is uniformly targeted by VPE in English. The only way that additional material, such as negation and non-finite auxiliaries, can survive is by cliticising to $\mathrm{T}^{\circ}$, thereby raising out of the ellipsis site. He claims that have, be and been optionally survive 
ellipsis by this optional cliticisation to $\mathrm{T}^{\circ}$. Since being is a prosodically heavy item, it cannot so easily cliticise to $\mathrm{T}^{\circ}$, which explains why it is obligatorily elided. ${ }^{26}$

The fundamental problem with this approach is that there is no evidence that be and been are able to undergo cliticisation to $\mathrm{T}^{\circ}$ in the same way that have can. Furthermore, this optional raising of be and been cannot capture the obligatory raising of these auxiliaries under VP fronting, an issue which we discuss in section 5 below.

\subsubsection{Sailor (2012)}

Like Thoms (2012), Sailor (2012) also assumes uniform lowering of affixes onto the auxiliaries through a Reverse Agree model, as in Bjorkman (2011). Sailor claims, however, that ellipsis targets the projection headed by the passive auxiliary, which is equivalent to $\mathrm{vP}$ in the hierarchy we assume. In order to explain obligatory ellipsis of being, Sailor proposes that being does not raise out of vP. He motivates this by claiming that the projection immediately above vP, ProgP, is headed by the progressive auxiliary in such instances. ${ }^{27}$ This prevents being from raising out of the ellipsis site as there is no available position for the auxiliary to raise to. In the case of passive be and been, Sailor assumes that ProgP still projects onto the clausal spine, but that its head is spelt out as null. Therefore $\operatorname{Prog}^{\circ}$ presents a potential position for the passive auxiliaries be and been to raise to. This raising out of the ellipsis site Sailor claims to be optional, accounting for the optional deletion of be and been.

The problems with Sailor's analysis are twofold: first, this optional raising of be and been to $\operatorname{Prog}^{\circ}$ is unmotivated. These auxiliaries have already checked their inflectional

\footnotetext{
${ }^{26}$ Thoms (2012) discusses some data where being actually survives VPE, something that was also pointed out to us by an anonymous reviewer. We present Thoms' view on this issue as well as our own in section 7.1.

Furthermore, as was pointed out to us by an anonymous reviewer, Thoms (and Bošković) can capture the dialectal variation that seems to occur with respect to have: as indicated above in section 3.2 there is some discussion about whether or not have can be deleted, and some speakers or certain dialects seem to allow for it. Our informants, however, did not accept this deletion, and with our analysis we capture the original pattern.

${ }^{27}$ Under the Reverse Agree analyses of the auxiliary system, auxiliaries are merged directly into the head of their associated aspectual projections, as no raising takes place. Therefore there is no need to posit vP shells.
} 
features in their base position of $v^{\circ}$ through Reverse Agree. Second, Sailor has no means of capturing the optional ellipsis of progressive be and been. His ellipsis site is $\mathrm{vP}$, which means that ProgP, which according to Sailor is headed by the progressive auxiliary, is outside of the ellipsis site. Therefore there is no way in which the progressive auxiliary can undergo ellipsis. Sailor (2012) responds to this by claiming that ellipsis of the progressive auxiliary is impossible, but as the data in section 3.1 has shown, this claim is false.

As said before, our account captures the auxiliary pattern, but also makes the interesting prediction that optional raising of be and been out of $\mathrm{vP}_{\text {prog }}$ is only made possible because of ellipsis, and that contexts without deletion would force the auxiliaries to raise and check their features. This is exactly what happens in VP fronting (VPF) cases, as section 5 shows, but none of the approaches presented above can account for this contrast between VPE and VPF.

\section{Extending the analysis}

\subsection{VP fronting}

A phenomenon that has been related to VPE in the literature is VP fronting (see Zagona 1982; Roberts 1990, 1998; Johnson 2001; Kim 2003; Aelbrecht \& Haegeman 2012; Funakoshi 2012; Aelbrecht 2012). It has been amply noted that VPE and VP fronting (VPF) exhibit parallel syntactic behaviour (Zagona 1982; Johnson 2001). They occur in the same environments: "both an elided VP and the trace left by a fronted VP must be governed by an Aux" (Johnson 2001: 444). Neither occurs without a modal, temporal auxiliary or $d o$-support, as the contrasts in (32) show (examples adapted from Aelbrecht 2012). ${ }^{28}$

\footnotetext{
${ }^{28}$ Or infinitival to, see Johnson (2001), Aelbrecht (2012), Aelbrecht \& Haegeman (2012) for examples. As was indicated in footnote 7 , we stay away from infinitival clauses in the present paper.
} 
(32) a. * I never thought I'd see Jess become a cook, but I saw [Jess become a cook].

b. * I never thought I'd see Jess become a cook, but [Jess become a ...] I saw $t$.

c. I never thought I'd see Jess become a cook, but I did [see ...].

d. I never thought I'd see Jess become a cook, but [see Jess become ...] I did $t$.

A second similarity between VPE and VPF is that both generally target the same chunk of the verb phrase. For instance, perfect have cannot be elided under VPE, and as (33)a,b, adapted from Johnson (2001:(19)), show, it cannot be fronted either. Moreover, Akmajian \& Wasow (1975) note that, just like VPE always deletes being, VPF cannot leave it behind, cf. (33)c,d.

(33) a. * Julia hadn't eaten fish, but Peter claimed that [have eaten fish] she should $t$.

b. Julia hadn't eaten fish, but Peter claimed that [eaten fish] she should have $t$.

c. Will thought he was being seduced and [being seduced] he was.

d. * Will thought he was being seduced and [seduced] he was being.

With this in mind, it is remarkable that VPF never optionally includes be or been in the fronted verbal structure, as observed by Akamajian, Steele \& Wasow (1979) and Roberts (1998). These auxiliaries are obligatorily stranded by the fronted constituent, see (34).

(34) a. * If he says he will be working all night, then [be working all night] he will.

b. If he says he will be working all night, then [working all night] he will be.

c. * If he says he has been working late, then [been working late] he has.

d. If he says he has been working late, then [working late] he has been. 
If VPE and VPF target the same chunk of the verb phrase, it is curious that VPE optionally includes be and been in this chunk, but VPF never does. This contrast can be easily captured under our analysis: optional deletion of be and been under VPE is due to the fact that the uninterpretable inflectional features on the auxiliaries are deleted at PF by ellipsis when the auxiliary does not raise out of the ellipsis site. Under VPF, however, the auxiliaries have to raise because there is no repair by ellipsis here. If they do not raise, their $[u \mathrm{~F}]$ features remain unchecked in the (moved) higher copy of the verb phrase, causing a crash at PF, see (35).

a. * He said he would be working all night and indeed [vP(pro be all night $]$ [те he [would [InfP $\operatorname{Inf}_{[i \operatorname{Inf}]}^{\circ} \mathrm{t}_{\mathrm{v}(\operatorname{prog})]]}$.

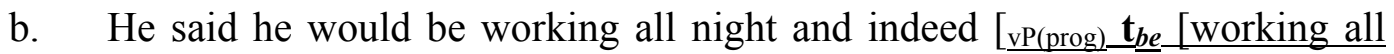

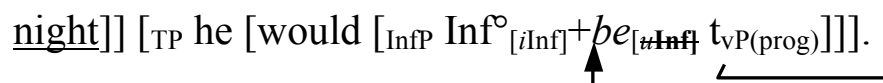

We consider this to be the most significant advantage of our approach over prior analyses. None of the alternative approaches reviewed in section 4.3 are able to explain the contrast between VPE and VPF straightforwardly. Bošković recognises in a footnote that there is a connection between VPE and fronting, though explicitly stays away from the issue. If we wish to maintain this link, however, in that the site targeted by VPE is the same site targeted by fronting, then be and been, which according to Bošković can be elided by optionally extending the ellipsis site to include them, are incorrectly predicted to be optionally fronted.

For Thoms (2012) and Sailor (2012) optional raising of auxiliaries out of the ellipsis site occurs independently of the ellipsis operation. Therefore auxiliaries should optionally raise in all contexts. This implies once again that be and been should optionally raise out the fronting site in VPF contexts, wrongly predicting optional fronting of these auxiliaries. 
Note that the analysis we have presented leads to an interesting prediction: under other phenomena making use of VPE, we expect the auxiliaries be and been to also be optionally elided, whereas in other phenomena involving movement of the VP, we expect the same auxiliaries to be obligatorily stranded. This is in fact confirmed by (American English) tag questions, which can be argued to involve VPE, and by both specificational pseudo-clefts and predicate inversion, which are claimed to involve movement of the verbal predicate.

\subsection{Extending the data range}

Let us first look at tag questions. Akmajian \& Wasow (1975) and Bošković (2004) have noted that in American English, the lexical verb and the passive/copular auxiliary being are always absent from tag questions, whilst non-finite have is always present (if the sentence being tagged contains perfect aspect, naturally), parallel to VPE: ${ }^{29}$

(36) a. Ted was being eaten by a gorilla, wasn't he (*being) (*eaten) by a gorilla?

b. Ted should have become a hot air balloon pilot, shouldn't he *(have)?

This has led Sailor (2009) to analyse tag questions as involving VPE. Interestingly, Sailor also notes that, just as with VPE, be and been occur optionally in tags:

(37) a. Ted has been eating dolphin sandwiches, hasn't he (been)? [Am Engl]

b. Ted will be eating dolphin sandwiches, won't he (be)?

\footnotetext{
${ }^{29}$ Interestingly, British English speakers behave differently. Their tag questions only contain the finite auxiliary. Unlike in American English, no non-finite auxiliaries remain, not even perfect have (Sailor 2009). British speakers judge the tags in (36)b and (37) only grammatical if have, be or been are absent. This is a remarkable contrast for which we will not try to provide an answer in this paper.
} 
This optional ellipsis of be and been conforms with our predictions.

Another context in which the verb phrase is fronted is specificational pseudo-clefting, as claimed by Blom \& Daalder (1977), Declerck (1988), Den Dikken (1995), Heggie (1988), Heycock (1994), Higgins (1979), Moro (1997) and Verheugd (1990) (cited in Den Dikken 2006). Sailor (2012) notes that, parallel to VPF, being is included in the moved phrase:

(38) Ted should be being praised. - No, *<being $>$ criticised is what he should be $<*$ being $>$.

(Sailor 2012:8)

Crucially, Sailor (2012) notes that be and been are obligatorily stranded in such constructions, again conforming with our predictions that auxiliaries only have the option of not raising in ellipsis contexts, in which their unchecked PF features can be deleted via ellipsis:

(39) a. Ted should be praised. - No, $<*$ be $>$ criticised is what he should $*<$ be $>$.

b. Ted should have been praised. - No, $<*$ been $>$ criticised is what he should have $*<$ been $>$.

(Sailor 2012:8)

A third context that has been argued to involve displacement of the predicate (i.e., the verb phrase in this case) is predicate inversion, see Hooper \& Thompson (1973), Emonds (1976), Heycock \& Kroch (1999) and Haegeman (2008). This phenomenon too patterns like VPF: being is obligatorily fronted with the inversed predicate, see (40).

(40) a. [Also being loud and obnovious today] is my old friend Bugs Bunny.

b. * [Also loud and obnoxious today] is being my old friend Bugs Bunny. 
As predicted by our analysis of these fronting contexts, be and been can never be included in the fronted constituent, see (41): these auxiliaries obligatorily raise out of $\mathrm{vP}_{\text {prog }}$ in order to check their inflectional features. If they do not, there is no ellipsis operation to rescue the derivation from a crash at $\mathrm{PF}$, so the resulting sentence is unacceptable.

(41) a. [Also with us in the studio today] will be my old friend Bugs Bunny.

b. * [Also be with us in the studio today] will my old friend Bugs Bunny.

c. [Also with us in the studio today] has been my old friend Bugs Bunny.

d. * [Also been with us in the studio today] has my old friend Bugs Bunny.

In sum, we have provided an analysis that accounts not only for the VP ellipsis paradigm of auxiliary verbs, but also for other cases with VPE, such as tag questions, and for auxiliary behaviour in phenomena involving movement of the verbal layer, such as VPF, specificational pseudo-clefts and predicate inversion.

In the next section we formalise how the ellipsis site is determined. We claim that the maximal ellipsis site is $\mathrm{vP}_{\text {prog }}$, but if the clause does not express progressive aspect, $\mathrm{vP}_{\text {prog }}$ and the ProgP selected by it are absent from the structure. This would make the ellipsis site smaller: VPE elides vP in that case. In other words, we do not assume a variable ellipsis site to account for the optionality of be/been deletion (unlike other proposals, such as Akmajian, Steele \& Wasow 1979 and Bošković to appear), but because we only take those aspectual projections which are expressed to be present in the syntax, the actual projection targeted by VPE does vary depending on what there is in the structure, that is, either $\mathrm{vP}$ or $\mathrm{vP}_{\text {prog. }}$ This makes it difficult to pin down exactly what the ellipsis site for VPE is, in a generalising statement. The next section presents a formalised solution for this issue. 


\section{6. $\quad$ Predicate ellipsis}

In section 3 we provided evidence for our claim that $\mathrm{vP}_{\text {prog }}$ is the maximal ellipsis site: when the clause contains progressive aspect, VPE targets $\mathrm{vP}_{\text {prog }}$ (see (42)a). When there is no progressive aspect in the clause, $\mathrm{vP}_{\text {prog }}$ and ProgP are absent, and VPE targets $\mathrm{vP}$, as in (42)b. This implies that the projection that is elided differs depending on what is present in the clause, making it harder to formalise how the ellipsis site is targeted.

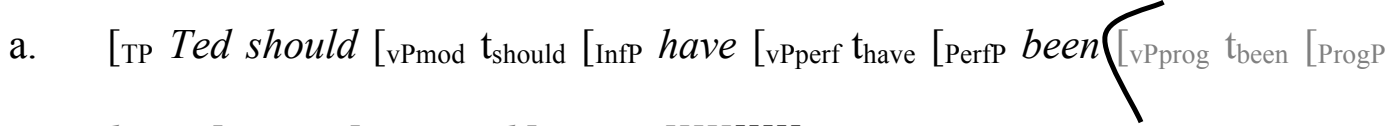
being [vp tbeing [voicep -ed [vp train]]]]]]]]]].

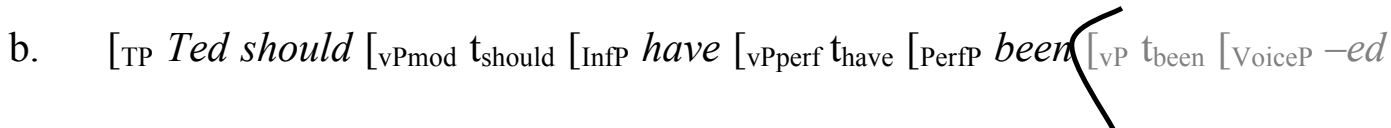
[vp train]]]]]]]].
}

The unsolved question of how the ellipsis site is determined is common to almost all approaches to VPE: although it might be empirically demonstrable which constituent is included in the VP ellipsis site, it remains a mystery why a specific projection is targeted. Our solution is that VPE always targets the highest projection of the clausal predicate.

\subsection{VPE is predicate ellipsis}

A brief look at the VPE literature reveals that it is not always a VP that is elided in VPE. Not every clause has a VP as its lexical core: many clauses have a predicative adjective, NP or PP as their lexical centre, but still allow for VPE in English, as (43) illustrates. 
(43) a. The door was $\{$ green/closed\}, but the window wasn't [green/closed].

b. Marshall could have been a pilot and Lily could have been [a pilot] too.

c. The chickens were in the garden, and the crocodile was [in the garden] too.

Of course, one can assume that these clauses still contain a vP hosting the copula, but whichever the label of that projection is, it is clear that what VPE elides is not necessarily a verb phrase, but rather it deletes the predicate of the clause. There is a certain degree of debate as to how large exactly the predicational layer should be. We follow Bowers (1993, 2001, 2002) in assuming that the predicational layer is comprised of VP (or AdjP, PP or NP in the case of a copular construction), as well as VoiceP and vP. Bowers (2002:204) also tentatively takes progressive aspect, when present, to constitute part of the predicational layer.

We therefore claim that VPE is predicate ellipsis, in that it targets the entire predicational layer (with the notion of predicate conforming to Bowers' 1993, 2001, 2002 assumptions) and that the progressive aspectual projections, but nothing higher, are part of this predicational layer. In what follows we show that progressive aspect behaves differently from other verbal aspects, and seems more closely connected to the predicate.

Firstly, progressive aspect is sensitive to lexical restrictions. Not all lexical verbs can occur with progressive aspect, while all verbs do allow perfect aspect. This suggests that the former is much more closely tied with the lexical verb than the latter.
a. I $\quad$ *am knowing/am learning $\}$ French.
[stative: *prog/dynamic: prog]
b. I have known/loved/sung that song for years. [stative: perf/dynamic: perf]

Another indication involves its morphological form in many languages: progressive formation (on the verb following the progressive phrase) seems to have more nominal 
properties than other verbal inflections. In English the -ing suffix makes clear the link with gerunds, which can be seen as nominalisations (to different degrees, see Chomsky 1970), as in (45)a. Also in other languages the progressive inflection has nominal properties, such as in Gungbe (see (45)b) (Aboh 2005), Dutch and German: in Dutch (see (45)c) for instance it comes with a definite article. Thus, it seems that in languages that express the progressive, its form is quite different from how verbal inflections normally behave in these languages, and seems to have some nominal properties.

(45) a. Ted('s) growing (of) a beard was the worst idea ever.

b. Kòjó tò àmì ló zân.

Kojo IMPERF oil DET NOMINALISER

'Kojo is using the oil.' (Aboh 2005:140)

c. De krokodil was aan het dansen.

the crocodile was on the dancing

'The crocodile was dancing.'

A third possible indication that progressive (and passive too) is part of the predicate, is that it uses BE as its auxiliary in English (and Dutch and other languages). This is identical to copular BE, which occurs with AP, NP and PP predicates. It is thus possible that progressive $\mathrm{BE}$ is simply another instance of a copular appearing alongside a verbal predicate, suggesting once again the predicational nature of the progressive. The perfect auxiliary in English on the other hand, is HAVE, which is rather distinct from the copular auxiliary, suggesting that perfect aspect, unlike progressive, is not a part of the predicate. ${ }^{30}$

\footnotetext{
${ }^{30}$ There are of course languages that use the auxiliary BE with perfect aspect too. However, many such languages do not display VPE in the first place. A prediction that one would make for languages with VPE that
} 
Having established that VPE is predicate ellipsis and that progressive aspect constitutes part of the predicational layer in English, we turn to a precise formalisation of how the ellipsis site is determined.

\subsection{Formalising the proposal}

The fact that the progressive aspectual layer is not always present implies that the size of the predicational layer can fluctuate depending on which projections are present in the derivation. Thus, to ensure that the entire predicational layer is elided each time VPE is applied, we claim that VPE always targets the highest projection of the predicational layer. ${ }^{31}$ In the presence of the progressive aspectual layer, this would mean that $\mathrm{vP}_{\text {prog }}$ is elided, and in the absence of it, $\mathrm{vP}$ is elided (or potentially VP, if one wants to assume that there is no $\mathrm{vP}$ in unaccussative clauses). In order to formalise this we turn to Grimshaw's $(2000,2005)$ extended projections in conjunction with the [E] feature for ellipsis licensing (Merchant 2001; Aelbrecht 2010).

\subsubsection{Preliminaries: The [E] feature and Extended Projections}

use the predicative copular as the perfect auxiliary, is that perfect aspect, unlike English, can be included in the ellipsis site. Rouveret (2012) shows that this is potentially the case for Welsh. Welsh, like English, exhibits VPE, but realises the perfect auxiliary as a form of BE. The particle realising perfect aspect can be ellided under VPE, suggesting that as much as perfect aspect is included in the ellipsis site (examples from Rouveret 2012 (44)):

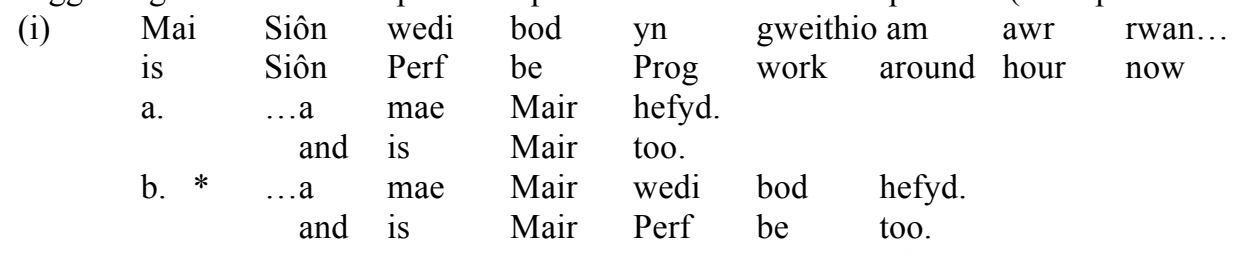

'Siôn has been working for an hour now and Mair has been too.'

Of course, these are not perfect examples since (i)b strands the progressive auxiliary as well, so we do not know whether the perfect particle is obligatorily or optionally elided: the ungrammaticality of (i)b could stem from the presence of the progressive auxiliary as well. Further investigation would be required.

Other languages to investigate in this respect are Serbo-Croatian, which has VPE and uses the same auxiliary for perfect sentences as for progressive, copular or passive ones. Even certain dialects of English, such as Hiberno-English, Shetland English and Newfoundland English use BE as the perfect auxiliary. This is an avenue for further research.

${ }^{31}$ This proposal might give us a way to - in the slightly longer run - formalise ellipsis without making use of the [E] feature, or to use it in a less stipulative way. At the moment, however, we do not know how to realise this. 
In his 2001 monograph, Merchant captures the licensing requirements on ellipsis by positing an [E] feature for ellipsis in the lexicon. Each type of [E] feature listed in the lexicon licenses a different type of ellipsis and is only compatible with a certain head. Specifically, the presence of an $[E]$ feature on a particular head marks the complement of that head for nonpronunciation at PF, i.e., ellipsis. For instance, sluicing is only allowed in wh-questions in English. Therefore, Merchant posits an $[\mathrm{E}]_{\mathrm{S}}$ feature for sluicing that is only compatible with a $[+$ wh, $+\mathrm{Q}] \mathrm{C}^{\circ}$ head. This head then acts as the licensor, and the $[\mathrm{E}]_{\mathrm{S}}$ feature marks the $\mathrm{TP}$ complement of this $\mathrm{C}^{\circ}$ head for non-pronunciation at $\mathrm{PF}$.

If this analysis is applied to English VPE, there is an [E] $]_{\mathrm{VPE}}$ feature for VPE which is only compatible with a $\mathrm{T}^{\circ}$ head (as it has been claimed that $\mathrm{T}^{\circ}$ licenses VPE, see Zagona 1988; Lobeck 1995; Johnson 2001; Merchant 2001, 2008b; Aelbrecht 2010 and many others). This [E] marks the complement of $\mathrm{T}^{\circ}$ for ellipsis, which under a minimal structure of C-T-v$\mathrm{V}$, would be $\mathrm{vP}$ - exactly the phrase that is standardly assumed to be targeted by VPE.

However, assuming the verbal structure can also include aspectual projections, applying this [E] feature to VPE is not so straightforward. As noted by Aelbrecht (2010), a problem with Merchant's (2001) [E] feature is that the licensing head for ellipsis is not necessarily always adjacent to the ellipsis site. This paper has demonstrated that various non-finite auxiliaries, namely have, be and been, can be stranded by VPE, intervening between the licensor $\mathrm{T}^{\circ}$ and the ellipsis site. Under our account, in which VPE maximally elides as much as $\mathrm{vP}_{\text {prog }}$, the modal and perfect aspectual layers can intervene between $\mathrm{T}^{\circ}$ and the ellipsis site. Aelbrecht (2010) solves this issue in the following manner: she claims that the [E] feature is merged on the head immediately c-commanding the ellipsis site. For VPE, Aelbrecht posits that the [E] feature licensing VPE is merged with Voice $^{\circ}$ (which sits above vP for her, as per Baltin 2012 and Merchant 2008a, 2013) rather than with $\mathrm{T}^{\circ}$. This [E] on Voice $^{\circ}$ marks its complement, $\mathrm{vP}$, for ellipsis. To capture the fact that $\mathrm{T}^{\circ}$ is required for $\mathrm{VPE}$ 
to be licensed, Aelbrecht claims that [E] bears an unchecked $[u \mathrm{~T}]$ feature which must be checked against $\mathrm{T}^{\circ}$ in order for ellipsis of $\mathrm{vP}$ to be licensed. ${ }^{32}$

We adopt Aelbrecht's (2010) [E] feature (but maintain the hierarchy established in (7)), with one alteration. Under Aelbrecht's proposal, it is no longer necessary that the [E] feature marks its complement for ellipsis. Instead, we propose that the [E] feature marks its own projection for ellipsis. So, if an $[\mathrm{E}]$ feature is present on $\mathrm{v}^{\circ}$, it agrees with $\mathrm{T}^{\circ}$ and marks the entire vP for non-pronunciation. We return to the $[E]$ feature shortly. In what follows we outline Grimshaw's $(2000,2005)$ theory of extended projections.

Grimshaw $(2000,2005)$ has proposed that the clausal spine be divided into a series of domains: extended projections. Essentially each lexical item - noun, adjective, adverb, verb or preposition - constitutes its own domain, and the functional items merged on top of this are merely extensions of this domain. So the lower bound of the domain is determined by the lexical item itself, and the higher bound is determined by the highest functional projection to be merged into the extended domain of the lexical item. An interesting trait of this proposal is that various properties and features of the lexical item at the foot of the extended domain can percolate up into the functional projections of the extended domain.

\subsubsection{Bringing it all together}

We assume that VPE targets the highest projection in the extended domain of the lexical predicate of the clause. ${ }^{33}$ We claimed that the progressive aspectual layer, but not the perfect,

\footnotetext{
${ }^{32}$ The [E] feature does not raise in order for this checking to take place. Rather, Aelbrecht (2010) posits that the [E] feature remains in its base position and checks itself against $\mathrm{T}^{\circ}$ via Reverse Agree, as per Adger (2003), Baker (2008), Haegeman \& Lohndal (2010), Bjorkman (2011), Merchant (2011), Wurmbrand (2011) and Zeijlstra (2008, 2010). However, Aelbrecht (2010) does not take Reverse Agree to be the only possible direction of agreement, as per Wurmbrand (2011) and Zeijlstra $(2008,2010)$. Instead she follows Haegeman \& Lohndal (2010) in assuming that the directionality of Agree may be paramaterised across and within languages. Since we will mainly be following Aelbrecht's (2010) proposal, we will also assume this: the [E] feature operates under Reverse Agree, but, as outlined in footnote 13, auxiliaries operate under Agree.
} 
is part of the predicational layer. This implies that, when progressive aspect is present in the derivation, $\mathrm{vP}_{\text {prog }}$ is the highest functional projection in the extended domain of the lexical predicate, and so is targeted by VPE. In the absence of progressive aspect, vP is the highest functional projection in this extended domain, and therefore vP is targeted by VPE. ${ }^{34}$

To explain how VPE is able to target these projections, we propose that the lexical predicate itself, whether a verb, adjective, preposition or noun, enters the derivation bearing an [E] feature which marks the phrase it projects for non-pronunciation. In accordance with Aelbrecht (2010), this feature must be checked against $\mathrm{T}^{\circ}$ in order for the ellipsis to be licensed. However, following Grimshaw's $(2000,2005)$ proposals, we claim that this [E] feature percolates up through every functional projection within the extended domain of the lexical predicate. In the presence of progressive aspect, the [E] feature percolates up through Voice ${ }^{\circ}, \mathrm{v}^{\circ}, \operatorname{Prog}^{\circ}$ and is ultimately inherited by $\mathrm{v}_{\text {prog }}{ }^{\circ}$. Because the projections above $\mathrm{vP}_{\text {prog }}$ are not part of the lexical predicate's extended projection, they are unable to inherit [E] (see (46)). Therefore the highest instance of [E] occurs on $\mathrm{v}_{\text {prog }}{ }^{\circ}$, marking $\mathrm{vP}_{\text {prog }}$ for ellipsis. From this position, the [E] feature agrees with $\mathrm{T}^{\circ}$ and ellipsis of $\mathrm{vP}_{\text {prog }}$ is licensed, as in (47). ${ }^{35}$

\footnotetext{
${ }^{33}$ This is similar to Bošković (to appear) who also takes VPE to target the highest projection in the extended domain of the lexical predicate. The difference is that he relates this to phase theory (Chomsky 2000, 2001), something which our analysis abstracts away from. Also, as mentioned in section 4.3.1, Bošković includes perfect aspect within the extended projection of the predicate, whereas we claim only as much as progressive aspect is included in the extended domain. As already discussed in section 4.3.1, this subtle difference in the size of the ellipsis site makes for a big difference when accounting for the relevant data.

${ }^{34}$ This implies that the domain above the predicate is determined by either the perfect aspectual layer, the modal layer, or $\mathrm{T}^{\circ}$, depending on what is present. This is problematic if one wishes to maintain the view that each domain has a lexical item at its core. Grimshaw $(2000,2005)$ suggests, however, that $\mathrm{T}^{\circ}$, and modals also, may be able to project their own domains, although perfect aspect remains a problem. On the other hand, Benveniste (1966), Freeze (1992), Kayne (1993) and others have proposed that the perfect auxiliary HAVE is comprised of BE plus a preposition. If prepositions constitute lexical items, this may explain how the perfect aspectual layer is able to start projecting its own domain and not be included in the extended domain of the lexical predicate.

${ }^{35}$ Instances of the [E] feature on the lower projections of the predicate domain also have an uninterpretable $[u T]$ to check. We claim that these are either checked by extension of the highest [E] feature being checked in a manner similar to copy chain formations (Chomsky 1995), or simply remain unchecked, but are elided anyway so they are no longer a problem for the derivation, similar to our proposal for be and been.
} 
(46)

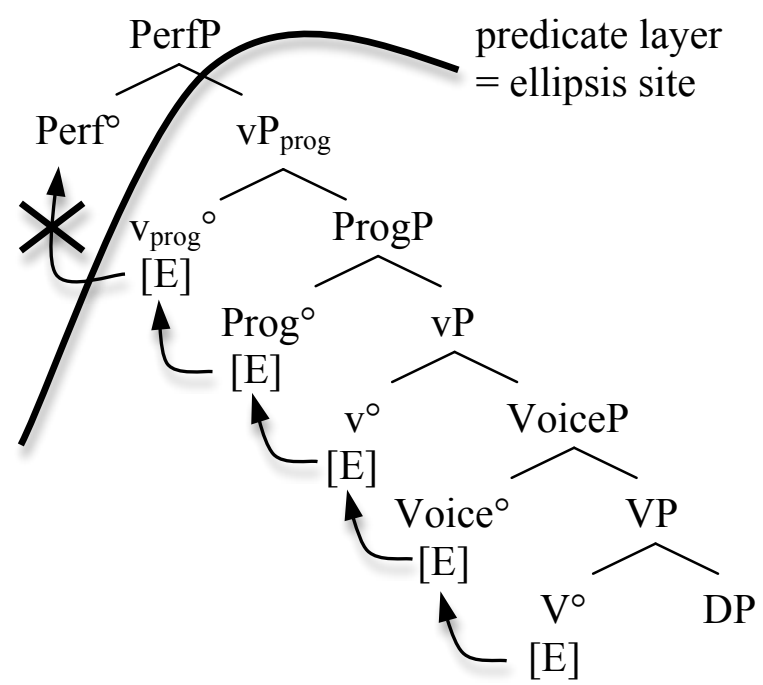

(47)

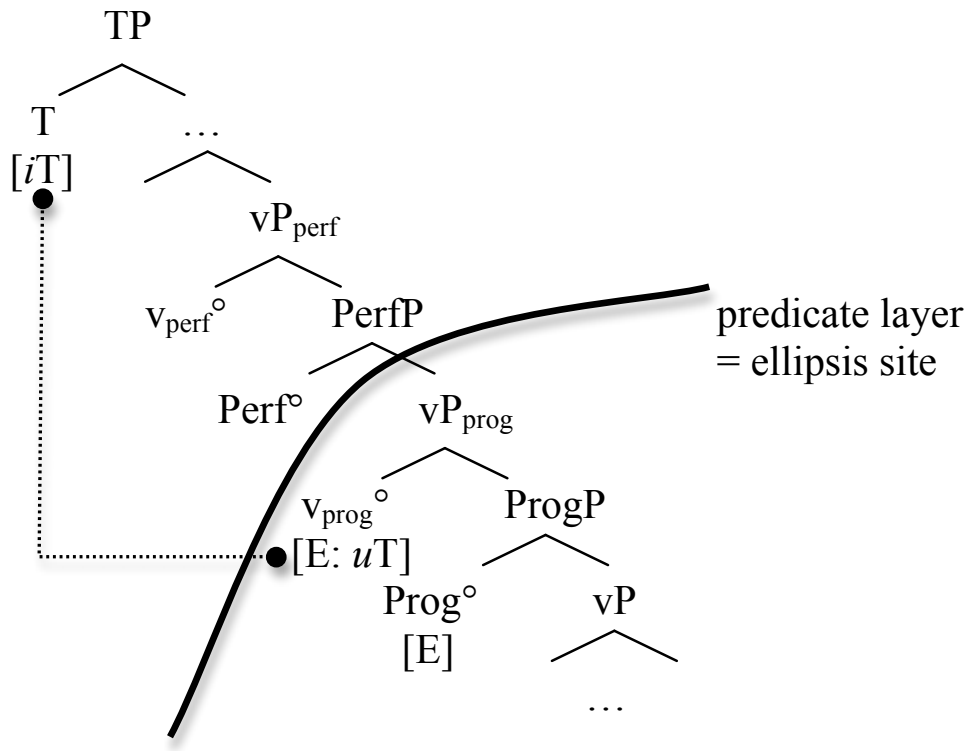

In the absence of progressive aspect, [E] percolates up as far as $\mathrm{v}^{\circ}$ (the highest functional projection of the predicate in this instance) where it agrees with $\mathrm{T}^{\circ}$ and marks vP for ellipsis.

To summarise, we assume VPE to in fact be predicate ellipsis (following Bowers' 1993, 2001, 2002 assumptions about the size of the predicate), and that progressive aspect, but no higher aspectual forms, constitutes part of the predicate. Crucially, VPE targets the highest projection in the extended domain of the lexical predicate. This is $\mathrm{vP}_{\mathrm{prog}}$ if progressive aspect is present, and vP otherwise. In ellipsis contexts we claim the lexical predicate is merged with 
an [E] feature bearing an uninterpretable $[u \mathrm{~T}]$ which must be checked against $\mathrm{T}^{\circ}$. [E] percolates up through the extended projection of the predicate to the head of the highest functional projection, which is either $\mathrm{v}_{\text {prog }}{ }^{\circ}$ or $\mathrm{v}^{\circ}$. From this position it agrees with $\mathrm{T}^{\circ}$ and licenses ellipsis of the phrase that it heads. ${ }^{36}$

\section{7. $\quad$ Further issues}

In this section we present some problematic issues that arise for our analysis and speculate about potential solutions to them. We first deal with instances in which being can apparently be stranded. Following this we discuss finite BE and voice mismatches.

\subsection{Being revisited}

When we presented the data for being in section 1, we already hinted at a complication (see footnote 4). As noted by an anonymous reviewer, Quirk et al (1975: 875) and Thoms (2012) observe that the deletion of being is not as categorical as it at first sight seems. Sometimes being can remain pronounced:

\footnotetext{
${ }^{36} \mathrm{An}$ issue that was pointed out to us by an anonymous reviewer that, as it stands, our analysis fails to account for, is Bresnan's (1976) generalisation stating that the VP ellipsis site needs to be adjacent to a head. Data supporting this view are given in (i).

(i) Don't worry about John - he'll have merely been delayed a while, and...

a. ...Pete'll have merely been, too.

b. * ...Pete'll have merely, too.

As suggested by the reviewer, to make our approach compatible with these data, we would need to postulate an additional constraint on the optional deletion of be and been. For reasons of space we do not cover this here.
} 
(48) a. Remember, always be respectful and courteous, even if the officer isn't being. ${ }^{37}$

b. Otherwise you may have some integrity problems because the key that apparently should be enforced actually isn't being.

Does that mean that being is in fact optionally elided, just like be and been? We take this not to be the case: whereas ellipsis of be and been is really optional when they have an identical antecedent, (as in (49)a,b; see Lasnik 1995), being is obligatorily elided when it has an identical antecedent (cf. (49)c), and is only stranded by ellipsis when its antecedent is nonidentical, as in (48) above and (49)d below:

(49) a. Ted should be home, and Barney should (be), too.

b. Ted has been fired, and Barney has (been), too.

c. Ted was being punished this morning, and now Barney is (*being).

d. Ted was punished this morning, and now Barney is being.

In other words, being survives ellipsis if it is not recoverable from the antecedent, parallel to be and been, as shown in (22). If it is recoverable however, it is obligatorily deleted, unlike be and been. To the extent that the stranding of being in (49) is acceptable, there are several ways to capture this fact. ${ }^{38}$ We first propose our own analysis before discussing that of Thoms' (2012).

\footnotetext{
${ }^{37}$ These examples were provided by an anonymous reviewer, who we thank. The first sentence can be found on $\mathrm{http} / / /$ www.uer.ca/forum_showthread_archive.asp?fid=13\&threadid $=79988 \&$ currpage $=2$, and the second one on $\mathrm{http}: / /$ consultingblogs.emc.com/jaceknieszporek/archive/2010/07/02/sql-server-and-unique-constrain-withmultiple-null-value-columns-part-ii.aspx.

${ }^{38}$ Judgements regarding the stranding of being in environments in which the auxiliary otherwise cannot be recovered are rather unstable. Whilst some speakers accept it, others find such sentences degraded, and certain other speakers outright reject such sentences.
} 
Under our analysis, ellipsis normally targets the entire predicational layer. However, when being is not recoverable, it is not possible to elide the $\operatorname{Prog}^{\circ}$ head hosting being, as that would violate the recoverability condition (see Merchant 2001, among many others). We suggest that in such cases only as much as vP is elided, so being survives ellipsis, preventing a violation of the recoverability condition. In other words, VPE targets as much of the predicate layer of the clause as possible (as an economy constraint, see also Takahashi \& Fox 2005 and Merchant 2008b, for the similar concept of MaxElide), but only the part that is recoverable. ${ }^{39}$ The fact that there is a conflict between these two requirements, namely "elide as much as possible" and the recoverability condition on ellipsis, might potentially account for the unstable judgements speakers give with regards to the stranding of being.

Potential support for the suggestion that ellipsis targets less in this case comes from the interaction of being-stranding with associates of existentials. The argument goes as follows: the derived associate of passive existentials precedes being, but follows been:

(50) Robin said that there had been many people being arrested.

To get the order been $>$ associate $>$ being $>\mathrm{V}$, the associate must have risen out of V's complement to a position in the progressive layer, preceding being. When VPE applies to existential sentences with being, both the associate and being are typically elided, as in (51)a. However, when being is not recoverable from the antecedent, it can survive ellipsis, see (51)b.

(51) a. Robin said that there were many people being arrested, and indeed, there were [vPprog many people being arrested].

\footnotetext{
${ }^{39}$ We are working on a way to formalise this, but a fully worked out proposal is deferred to future research.
} 
b. Robin said that there will be more people arrested tomorrow than there are being [vp people arrested] now.

According to our proposal, being can survive here because VPE targets $\mathrm{vP}$, not $\mathrm{v}_{\text {prog }}$, due to recoverability restrictions. This predicts that the associate, which usually raises to a position within the progressive layer, should also be able to survive ellipsis when it occupies this position, despite being recoverable. To the extent that being can be stranded, this prediction is borne out, at least for half of our informants:

Robin said that there will be more people arrested tomorrow than there are [vProg people being [vP tpeoplearrested] $_{\text {pow. }}$

What happens here is the following: parallel to be and been, the associate raises out of its base position for feature checking. When VPE targets $\mathrm{vP}$ instead of $\mathrm{vP}_{\text {prog }}$, the associate has two options: either it raises to the progressive layer to check the feature and survive VPE, or it remains in VP and is deleted, together with the unchecked feature. ${ }^{40}$ This indicates that VPE can target $\mathrm{vP}$ instead of $\mathrm{vP}_{\text {prog }}$ when the progressive layer contains material that is not recoverable. $^{41}$

\footnotetext{
${ }^{40}$ Three remarks are in order here. First, this analysis implies that the feature checked by the associate has to be one that is relevant only for PF. That is not too controversial, given that raising of the associate does not seem to have any semantic implications. If this hypothesis is on the right track, it could give us more insight into the nature of the movement of the associate.

A second remark has to do with the speakers for whom (52) is ungrammatical. One could argue that speakers differ in how strong constraints are for them. Variation could be due to an individiual's sensitivity to the recoverability requirement and/or the requirement that one should elide as much of the predicate as possible.

Thirdly, an apparent counterexample to our generalisation that being can only survive ellipsis when it is absent from the antecedent is the following:

(i) If Ted wasn't being difficult, then who WAS (being)?

Being occurs in the antecedent and still it can survive VPE. However, this seems to be restricted to this specific construction with 'if...then'. At this point we do not know how to analyse this data.

${ }^{41}$ Another potential application of the same idea could involve British English do. Haddican (2007), Baltin (2012) and Aelbrecht (2010) have argued that British English do sits in little $v^{\circ}$, and that the ellipsis site is VP.
} 
Of the alternative analyses reviewed in section 4.3 , the only one which deals with the apparent stranding of being is that of Thoms (2012). We briefly discuss his approach. As mentioned in section 4.3.2, Thoms (2012) takes movement of the finite auxiliary to $\mathrm{T}^{\circ}$ to be the licensor for VPE, and non-finite auxiliaries survive VPE by optionally cliticising to $\mathrm{T}^{\circ}$. Being normally does not move, and therefore does not survive ellipsis, but in these rather rare occasions when it does remain pronounced, Thoms claims that being cliticises to $\mathrm{T}^{\circ}$ too. In this case the finite auxiliary bears extra stress to host the prosodically heavy being as a clitic.

However, there are some problems with this proposal. First of all, apart from it being quite an ad hoc stipulation to assume that being cliticises to $\mathrm{T}^{\circ}$ (without any actual prosodic difference) Thoms' (2012) proposal depends on the fact that the finite auxiliary in particular bears extra stress so as to host being. Although we do not want to deny that prosody is at stake here, the finite auxiliary is not the only item that can bear such stress. In the sentence in (49)d, for instance, the finite auxiliary is preceding being is not contrasted; the subject is.

Secondly, both floating quantifiers (FQs) and associates from existential constructions can intervene between being and $\mathrm{T}^{\circ}$, as in (53). This casts doubt on the claim that being has cliticised to $\mathrm{T}^{\circ}$, unless one wants to assume that FQs and associates could also cliticise to $\mathrm{T}^{\circ}$. Given the particular emphasis on the associate, however, this seems unlikely.

(53) a. Ted said they would all be arrested, and they ARE all being.

b. Ted says there will be more men arrested tomorrow than there are $<$ WOMEN $>$ being now. 
Thirdly, Thoms' (2012) approach has nothing to say about the fact that survival of being appears to be subject to recoverability conditions, as we have argued.

\subsection{Finite $\mathrm{BE}$}

A second issue involves finite $\mathrm{BE}$, which we have already briefly mentioned in section 4.1. Our approach to optional be/been deletion was that be and been have the option of not raising to check their inflectional features, because ellipsis would elide the unchecked features and prevent the PF violation anyway. That means, however, that finite BE would have that option as well, which predicts that finite BE could optionally be elided. This is not the case, as VPE can never elide the finite auxiliary. One could say that $\mathrm{T}^{\circ}$ needs to be filled by postulating that there is an unchecked feature on the head itself which must be checked by the auxiliary (perhaps the verbal equivalent of an EPP feature, see Nunes \& Zocca 2005, 2009; Bjorkman 2011; Wurmbrand 2011). If the auxiliary does not raise, this feature on $\mathrm{T}^{\circ}$ goes unchecked, causing a PF violation, and as it is not within the ellipsis site, it cannot be rescued by ellipsis.

In relation to this, one could wonder how this feature on $\mathrm{T}^{\circ}$ is checked in the case of finite lexical verbs, which are standardly assumed not to raise beyond the vP domain in English. To answer this we follow Lasnik (1995b), who suggests that auxiliaries enter the derivation inflected and license their inflectional form through feature checking, whereas lexical verbs are introduced bare and get their inflection through linearisation. Hence, for Lasnik there are two kinds of inflection: featural and affixal, for auxiliaries and lexical verbs respectively. This means that the lexical verb itself would be devoid of an uninterpretable inflectional feature, and the interpretable counterpart higher on the clausal spine would also be entirely absent from the derivation as well, replaced instead by an inflectional affix. This implies that in the case of finite lexical verbs, the unchecked verbal feature on $\mathrm{T}^{\circ}$ might also 
be absent, so there is no requirement for a verb to occupy $\mathrm{T}^{\circ}$ in such instances. $\mathrm{T}^{\circ}$ is then only headed by the finite affix itself, which attaches to the lexical verb via linearisation. In cases of ellipsis or negation, when $d o$-support occurs, the finite inflection cannot attach directly to the lexical verb, so dummy do is inserted as a last resort PF operation to host the finite inflection.

One final question is why the option of $d o$-support is never available for finite auxiliaries. That is, why are finite auxiliaries required to raise to $\mathrm{T}^{\circ}$ rather than rely on insertion of dummy do directly into $\mathrm{T}^{\circ}$ like finite lexical verbs? The answer here could be that insertion of dummy do into $\mathrm{T}^{\circ}$ is a more costly operation than auxiliary raising: unlike the auxiliaries, do was never a part of the original numeration and is simply a PF operation to save the derivation as a last resort. Auxiliary raising to satisfy $\mathrm{T}^{\circ}$ 's unchecked feature, which is an option unavailable to the lexical verb, is a less costly operation than insertion of an extra item at $\mathrm{PF}$, therefore auxiliary raising is chosen over do insertion, so the finite auxiliary does not have the option of staying in situ under ellipsis.

Related to this is the issue of why this distinction between lexical and auxiliary verbs should exist in English in the first place. It is standardly assumed that universal grammar categorially distinguishes lexical verbs from auxiliary verbs (see Akmajan, Steele \& Wasow 1979; Steele 1981; Kayne 1989; Lasnik 1995b; see also Roberts 1998). ${ }^{42}$ Why there is such a contrast, however, has been a long standing issue for generative syntax, and one which we are unfortunately unable to answer in this paper. ${ }^{43}$

\footnotetext{
42 Wexler (1994) observed a consistent pattern of inflectional errors in child English reflecting such a fundamental contrast between English main verbs and auxiliaries: children freely substitute the infinitival form for the appropriate finite form for main verbs, but not for auxiliaries.

${ }^{43}$ Regarding finite verbs, another issue we cannot discuss here for reasons of space, has to do with epistemic modals. It has been argued that epistemic modals do not allow for VPE, at least not without the presence of a non-finite auxiliary (see for instance Gergel 2009). It is not clear how our analysis would straightforwardly account for this, but in fact, this claim itself is rather controversial. In their authorative grammar of English, Huddleston and Pullum (2002: 1520 (4i)) give the example in (i)a, and there are plenty of other examples like it (thanks to Liliane Haegeman for pointing them out to us). We defer this discussion to future research.
}

(i) a. A: They must have made a mistake. - B: Yes, they must.

b. 'There must be something wrong with you,' Ronald said. 'So there must.' (Muriel Spark, The Bachelors, Macmillan 1960 Penguin edn 1963, 170) 


\subsection{Voice mismatches}

One final issue for our proposal involves voice mismatches under VPE. Merchant (2008a, 2013) notes that voice mismatches between antecedent and ellipsis clause are possible under ellipsis: the antecedent clause may be active, whilst the ellipsis clause bares passive voice, and vice versa (but see Kehler 2002 for restrictions on voice mismatches).

(54) a. The janitor must remove the trash whenever it is apparent that it should be [removed]. (Act-Pass)

b. The system can be used by anyone who wants to [use it].

(Pass-Act)

Merchant accounts for this mismatch by claiming that VoiceP, encoding the passive or active status of the clause, is contained outside of the ellipsis site and is therefore not subject to the recoverability requirement of ellipsis. That is, because VoiceP survives ellipsis, it does not need to be identical in form to the VoiceP contained in the antecedent. The problem for our analysis is that VoiceP is always contained within the ellipsis site, whether that be $\mathrm{vP}$ or $\mathrm{vP}_{\text {prog. }}$ This implies that VoiceP should be subject to the identity condition, so we expect voice mismatches between the antecedent and the ellipsis clause to be illicit, contrary to fact.

Although we do not have any easy solution to this issue, one interesting point to note is that voice mismatches are illicit with progressive aspect, but not with higher aspectual forms,

c. What is empathy? You may feel it when Oliver Twist asks for more gruel, though you may not when a banker demands a bonus. (Observer 1.4 .12 page $37 \mathrm{col} 1$ ) 
such as perfect aspect, see (55). ${ }^{44}$ This observation highlights the peculiar and somewhat unique behaviour of progressive aspect that we have only just begun to touch on in this paper.

(55) a. The system can't be used by just anyone, even though Mary has [used the system] already twice.

b. * The system can't be used by just anyone, even though Mary has been [using the system] all year.

\section{Conclusion}

In conclusion, this paper accounts for the fact that under VPE, modals, finite auxiliaries and perfect have can never be elided, being is standardly always elided, and be and been are optionally elided. This was achieved by claiming that ellipsis targets as much as $\mathrm{vP}_{\text {prog }}$ (though less if progressive aspect is absent from the underlying derivation). We also assumed that auxiliaries uniformly raise in English to check uninterpretable (PF) inflectional features, and explained the relevant ellipsis data as follows: being's base position and landing site are both contained within the ellipsis site; have is basegenerated outside of the ellipsis site; and be and been's base positions are inside the ellipsis site, but they raise out. Their optional deletion comes down to optional raising: they either raise out of the ellipsis site to check their features and survive ellipsis, or they remain inside the ellipsis site and have their features deleted at PF by ellipsis. This option is not available to be and been under fronting phenomena however, since no ellipsis occurs to delete their unchecked features. Finally, as a means of formalising the ellipsis site, we argued that VPE is in fact predicate ellipsis, and that progressive aspect may be seen as part of the predicate whilst higher aspectual forms are not.

\footnotetext{
${ }^{44}$ Thanks to Jason Merchant (p.c) and Wurmbrand (2012) for pointing out this observation.
} 
Formally, we claimed that the lexical predicate is merged bearing an [E] which percolates up to the head of the highest functional projection within the extended domain of the predicate. In this position, $[\mathrm{E}]$ is checked against $\mathrm{T}^{\circ}$ and marks its own projection for non-pronunciation, thereby eliding the entire predicational layer of the clause.

\section{References}

Aboh, Enoch. 2005. Object shift, verb movement and verb reduplication. In Guglielmo Cinque \& Richard Kayne (eds.), The Oxford handbook of comparative syntax. 138- 177. New York: OUP.

Adger, David. 2003. Core Syntax. Oxford: Oxford University Press.

Aelbrecht, Lobke. 2010. The Syntactic Licensing of Ellipsis. Amsterdam: John Benjamins.

Aelbrecht, Lobke. 2012. Movement or ellipsis: What's the difference?! Ms. Ghent University. Aelbrecht, Lobke \& Liliane Haegeman. 2012. VP ellipsis is not licensed by VP Topicalization. Linguistic Inquiry 43(4).

Aissen, Judith. 1975. Presentational there-insertion: a cyclic root transformation. Proceedings of CLS 11, 1-14.

Akmajian, Adrian \& Thomas Wasow. 1975. The constituent structure of VP and AUX and the position of BE. Linguistic Analysis 1, 205-245.

Akmajian, Adrian, Susan Steele \& Thomas Wasow. 1979. The category AUX in Universal Grammar. Linguistic Inquiry 10, 1-64.

Baker, Mark C. 1988. Incorporation: a theory of grammatical function changing. Chicago: University of Chicago Press.

Baker, Mark. 1997. Thematic Roles and Syntactic Structure. In Liliane Haegeman (ed.), Elements of Grammar, 73-137. Dordrecht: Kluwer. 
Baker, Mark. 2003. Building and Merging, not Checking: the nonexistance of (Aux)-S-V-O languages. Linguistic Inquiry 33, 321-329.

Baker, Mark C. 2008. The Syntax of Agreement and Concord. Cambridge University Press.

Baltin, Mark. 2012. Deletion versus pro-forms: an overly simple dichotomy? Natural Language and Linguistic Theory 30. 381-423.

Benveniste, Émile. 1966. Problèmes de linguistique générale. Paris: Gallimard.

Bjorkman, Bronwyn. 2011. BE-ing default: The morphosyntax of auxiliaries. $\mathrm{PhD}$ dissertation, MIT.

Blom, Alied \& Saskia Daalder. 1977. Syntaktische theorie en taalbeschrijving. Muiderberg: Coutinho.

Bošković, Željko. 2004. Be careful where you float your quantifiers. Natural Language and Linguistic Theory 22. 681-742.

Bošković, Željko. 2007. On the locality and motivation of Move and Agree: An even more minimal theory. Linguistic Inquiry 38. 589-644.

Bošković, Željko. To appear. Now I'm a phase, now I'm not a phase: On the variability of phases with extraction and ellipsis. Linguistic Inquiry.

Bowers, John. 1993. The syntax of predication. Linguistic Inquiry 24:591-656.

Bowers, John. 2001. Predication. In Mark Baltin \& Chris Collins (eds.), The Handbook of Contemporary Syntactic Theory, 299-333. Oxford: Blackwell.

Bowers, John. 2002. Transitivity. Linguistic Inquiry 33. 183-224.

Bresnan, Joan. 1976. The form and functioning of transformations. Linguistic Inquiry 7, 3-40.

Caponigro, Ivano \& Carson T. Schütze. 2003. Parameterizing passive participle movement. Linguistic Inquiry 34(2).

Chomsky, Noam. 1970. Remarks on nominalization. In Roderick Jacobs \& Peter Rosenbaum (eds.), Readings in English Transformational Grammar. Waltham, MA: Blaisdell. 
Chomsky, Noam. 1986. Barriers. The MIT Press.

Chomsky, Noam. 1993. A Minimalist Program for Linguistic Theory. In Ken Hale \& S. Jay Keyser (eds.), The View from Building 20: Essays in Linguistics in Honor of Sylvain Bromberger. Cambridge: MIT Press.

Chomsky, Noam. 1995. The Minimalist Program. Cambridge MA: MIT Press.

Chomsky, Noam. 2000. Minimalist inquiries. In Roger Martin, David Michaels \& Juan Uriagereka (eds.), Step by step, 89-155. Cambridge: MIT Press.

Chomsky, Noam. 2001. Derivation by phase. In Michael Kenstowicz (ed.), Ken Hale: A life in language. Cambridge: MIT Press.

Cinque, Guglielmo. 1999. Adverbs and Functional Heads: A Cross-Linguistic Perspective. Oxford: Oxford University Press.

Cyrino, Sonia \& Gabriella Matos. 2005. Local licensers and recovering in VP ellipsis. Journal of Portuguese Linguistics 4(2). 79-112.

Deal, Amy. 2009. The origin and content of expletives: evidence from "selection". Syntax 12.

Declerck, Ranaat. 1988. Studies on Copular Sentences, Clefts and Pseudo-Clefts. Leuven: Leuven University Press/Foris Publications.

Dikken, Marcel den. 1995. Copulas. Ms. Vrije Universiteit Amsterdam/HIL.

Dikken, Marcel den. 2006. Specificational copular sentences and pseudo-clefts. In Martin Everaert and Henk van Riemsdijk, eds., The Blackwell companion to syntax, 4. Blackwell.

Eide, Kristin \& Tor Åfarli. 1997. A predication operator: evidence and effects. Ms, NTNU.

Emonds, Joseph. 1976. A transformational approach to English syntax. New York: Academic Press.

Freeze, Ray. 1992. Existentials and other locatives. Language 68. 553-595.

Funakoshi, Kenshi. 2012. On Headless XP-Movement/Ellipsis. Linguistic Inquiry 43(4). 
Gardent, Claire. 2000. Deaccenting and Higher-Order Unification. Journal of Logic, Language and Information 9(3), 313-338.

Gengel, Kirsten. 2007. Focus and Ellipsis: A Generative Analysis of Pseudogapping and other Elliptical Structures. PhD dissertation, University of Stuttgart.

Gergel, Remus. 2009. Modality and Ellipsis. Diachronic and Synchronic Evidence. Berlin/New York: Mouton de Gruyter.

Grimshaw, Jane. 2000. Locality and extended projection. In Peter Coopmans, Martin Everaert and Jane Grimshaw, (eds.), Lexical specification and insertion, 115-133. Amsterdam/Philadelphia: John Benjamins.

Grimshaw, Jane. 2005. Words and Structure. Chicago: CSLI Publications.

Haddican, William. 2007. The structural deficiency of verbal pro-forms. Linguistic Inquiry 38. 539-547.

Haegeman, Liliane. 2008. Prenominal possessors and predicate inversion in the West Flemish DP. Paper presented at CASTL Research Center, University of Tromsø.

Haegeman, Liliane, and Terje Lohndal. 2010. Negative concord and (multiple) agree: a case study of West Flemish. Linguistic Inquiry 41. 181-211.

Hardt, Daniel. 2005. Inference, Ellipsis and Deaccenting. Amsterdam Colloquium 2005.

Harwood, William. 2011. Phasage: a phase based account of English existential constructions. Proceedings of SICOGG 13.

Harwood, William. 2012. There are several positions available: English intermediate subject positions. In Proceedings of ConSOLE XIX.

Harwood, William. 2013. Rise of the Auxiliaries: A Case for Auxiliary Raising vs. Affix Lowering. Ms. Ghent University. 
Harwood, William. To appear. Rise of the associate: an analysis of English existential constructions. In Carissa Abrego-Callier, Martina Martinović et al (eds.), Proceedings of CLS 47, Chicago: Chicago Linguistic Society Press.

Heggie, Lorie. 1988. The Syntax of Copular Structures. PhD dissertation, University of Southern California.

Heycock, Caroline. 1994. The internal structure of small clauses. Proceedings of NELS 25, 223-38. Amherst: GLSA.

Heycock, Caroline \& Anthony Kroch. 1999. Pseudocleft Connectivity: Implications for the LF Interface. Linguistic Inquiry 30(3), 365-397.

Higgins, Francis Roger. 1979. The Pseudo-Cleft Construction in English. New York: Garland.

Holmberg, Anders. 2001. The syntax of Yes and No in Finnish. Studia Linguistica 55. 140174.

Hooper, Joan \& Sandra Thompson. 1973. On the applicability of root transformations. Linguistic Inquiry 4: 465-497.

Huddleston, Rodney \& Geoffrey Pullum. 2002. The Cambridge Grammar of the English Language. Cambridge: Cambridge University Press.

Iwakura, Kunihiro. 1977. The auxiliary system in English. Linguistic Analysis 3. 101-136.

Johnson, Kyle. 2001. What VP-ellipsis can do, and what it can't, but not why. In Mark Baltin \& Chris Collins (eds.), The handbook of contemporary syntactic theory, 439-479. Oxford/Boston: Blackwell.

Johnson, Kyle. 2004. How to be Quiet. In Nikki Adams, Adam Cooper, Fey Parrill \& Thomas Wier (eds.), Proceedings from the 40th Annual Meeting of the Chicago Linguistics Society, $1-20$.

Kayne, Richard. 1989. Notes on English Agreement. Ms, CUNY Graduate Center. 
Kayne, Richard. 1993. Toward a modular theory of auxiliary selection. Studia Linguistica, 47. $3-31$.

Kehler, Andrew. 2002. Coherence, reference, and the theory of grammar. Stanford, CA: CSLI.

Kim, Jong-Bok. 2003. Negation, VP ellipsis and VP fronting in English. A construction HPSG analysis. The Korean Generative Grammar Circle. 271-282.

Kratzer, Angelika. 1996. Severing the external argument from its verb. In Johan Rooryck and Laurie Zaring, (eds.), Phrase Structure and the Lexicon. 109-137. Dordrecht: Kluwer.

Lasnik, Howard. 1995a. A note on pseudogapping. Papers on Minimalist Syntax, MIT Working Papers in Linguistics 27. 143-163.

Lasnik, Howard. 1995b. Verbal morphology: Syntactic Structures meets the minimalist program. In Hector Campos \& Paula Kempchinsky (eds.), Evolution and Revolution in Linguistic Theory: Essays in Honor of Carlos Otero, 251-275. Georgetown University.

Lasnik, Howard. 1999. Pseudogapping puzzles. In Shalom Lappin and Elabbas Benmamoun (eds.), Fragments: Studies in Ellipsis and Gapping, 141-174. Oxford University Press.

Lasnik, Howard. 2001. When can you save a structure by destroying it? In Minjoo Kim \& Uri Strauss (eds.), Proceedings of the North East Linguistics Society 31, 301-320. GLSA.

Law, Paul. 1999. On the passive existential constructions. Studia Linguistica 53.183-208.

Lobeck, Anne. 1987. Syntactic Constraints on VP Ellipsis. PhD Dissertation, Indiana University.

Lobeck, Anne. 1995. Ellipsis: Functional Heads, Licensing and Identification. Oxford: Oxford University Press.

McNally, Louise. 1992. An interpretation for the English existential construction. $\mathrm{PhD}$ Dissertation, University of California, Santa Cruz. 
Merchant, Jason. 2001. The syntax of silence. Sluicing, islands and the theory of ellipsis. Oxford: Oxford University Press.

Merchant, Jason. 2008a. An asymmetry in voice mismatches in VP-ellipsis and pseudogapping. Linguistic Inquiry 39(1). 169-179.

Merchant, Jason. 2008b. Variable island repair under ellipsis. In Kyle Johnson (ed.), Topics in ellipsis, 132-153. Cambridge: Cambridge University Press.

Merchant, Jason. 2011. Aleut case matters. In Etsuyo Yuasa Yuasa, Tista Bagchi, and Katharine P. Beals, (eds.), Pragmatics and Autolexical Grammar: in honor of Jerry Sadock. 382-411. Amsterdam: John Benjamins.

Merchant, Jason. 2013. Voice and ellipsis. Linguistic Inquiry 44. 77-108.

Milsark, Gary. 1974. Existential sentences in English. PhD dissertation, MIT.

Moro, Andrea. 1997. The raising of predicates: predicative noun phrases and the theory of clause structure. Cambridge: Cambridge University Press.

Müller, Gereon. 2011. Constraints on Displacement. A Phase-Based Approach. Amsterdam: John Benjamins.

Nunes, Jairo and Cynthia Zocca. 2005. Morphological identity in ellipsis. In Noureddine Elouazizi, Frank Landsbergen, Mika Poss and Martin Salzmann (eds.), Leiden Papers in Linguistics, 29-42. Leiden: Leiden University.

Nunes, Jairo and Cynthia Zocca. 2009. Lack of morphological identity and ellipsis resolution in Brazilian Portuguese. In Jairo Nunes (ed.), Minimalist Essays on Brazilian Portuguese Syntax, 215-236. Amsterdam/Philadelphia: John Benjamins.

Quirk, Randolph, Sidney Greenbaum, Geoffrey Leech \& Jan Svartik. 1972. A Grammar of Contemporary English. London: Seminar Press.

Rezac, Milan. 2006. The interaction of Th/Ex and locative inversion. Linguistic Inquiry 37(4). Rizzi, Luigi. 1990. Relativized Minimality. MIT Press. 
Roberts, Ian. 1990. Some Notes on VP-Fronting and Head-Government. In Javier Mascarò \& M. Nespor (eds), Progress in Grammar: A Festschrift for Henk van Riemsdijk, 387-396. Dordrecht: Foris.

Roberts, Ian. 1998. Have/be raising, move F, and procrastinate. Linguistic Inquiry 29, 113125.

Ross, John. 1969. Auxiliaries as main verbs. In William Todd (ed.), Studies in philosophical linguistics (Series 1). Evanston, IL: Great Expectations Press.

Rouveret, Alain. 2012. VP ellipsis, phases and the syntax of morphology. Natural Language and Linguistic Theory, 30(3). 897-963.

Sag, Ivan. 1976. Deletion and Logical Form. PhD dissertation, MIT.

Sailor, Craig. 2009. Tagged for Deletion: A Typological Approach to VP Ellipsis in Tag Questions. Ma thesis, UCLA.

Sailor, Craig. 2012. Inflection at the interface. Ms. UCLA.

Steele, Susan. 1981. An Encyclopedia of Aux. Cambridge: MIT Press.

Takahashi, Shoichi \& Danny Fox. 2005. MaxElide and the re-binding problem. Semantics and Linguistic Theory 15: 223-240.

Tancredi, Chris. 1992. Deletion, deaccenting, and presupposition. PhD Dissertation, MIT.

Thoms, Gary. 2011. Verb-floating and VPE: towards a movement account of ellipsis licensing. Linguistic Variation Yearbook 2011.

Thoms, Gary. 2012. Towards a movement theory of ellipsis licensing. Paper presented at UiLOTS, Utrecht.

Travis, Lisa. 1984. Parameters and effects of word order variation. PhD dissertation, MIT.

Verheugd, Els. 1990. Subject Arguments and Predicate Nominals: a study of French copular sentences with two NPs. Amsterdam: Rodopi.

Warner, Anthony R. 1986. Ellipsis Conditions and the Status of the English Copula. York 
Papers in Linguistics 12. 153-172.

Wexler, Kenneth. 1994. Optional Infinitives, Head Movement, and the Economy of Derivations. In David Lightfoot \& Norbert Hornstein (eds.), Verb Movement. Cambridge: Cambridge University Press.

Williams, Edwin. 1984. There-insertion. Linguistic Inquiry 15. 131-153.

Wurmbrand, Susi. 2011. On Agree and Merge: lecture notes. University of Connecticut.

Wurmbrand, Susi. 2012. Seminar on Agree, Merge \& Phasehood. University of Connecticut.

Wurmbrand, Susi. To appear. The syntax of valuation in auxiliary-participle constructions. In Coyote Working Papers: Proceedings of the $29^{\text {th }}$ West Coast Conference on Formal Linguistics. University of Arizona, Tucson.

Zagona, Karen. 1982. Government and proper government of verbal projections. $\mathrm{PhD}$ dissertation, University of Washington.

Zagona, Karen. 1988. Verb Phrase Syntax: a Parametric Study of Spanish and English. Dordrecht: Kluwer.

Zeijlstra, Hedde. 2008. Negative concord is syntactic agreement. Ms. University of Amsterdam.

Zeijlstra, Hedde. 2010. There is only one way to agree. Talk given at GLOW 33, Wroclaw, Poland.

Zeijlstra, Hedde. 2011. On the uninterpretability of interpretable features. Paper presented at the University of Potsdam, October 2011. 